\title{
Reseña de Sentencias del Tribunal Constitucional sobre la Administración Local y Autonómica que aparecen publicadas en el BOE durante el primer semestre de 1997
}

\author{
Francisco Javier Fernández González \\ Profesor Titular de Derecho Administrativo \\ Universidad de Oviedo
}

Sumario: I. ENTES PÚBLICOS: A) Derechos Fundamentales. B) Prerrogativas. II. EMPLEO PÚBLICO. III. JURISDICCIÓN CONTENCIOSO-ADMINISTRATIVA. IV. RÉGIMEN ELECTORAL. V. DERECHO SANCIONADOR. VI. DERECHO URBANISTICO. VII. DERECHO PÚBLICO DE LA ECONOMÍA: A) Agricultura. B) Comercio. C) Energía. Petroleo. D) Entidades de Crédito. VIII. MEDIO AMBIENTE. IX. CULTURA. X. UNIVERSIDADES. XI. LENGUAS.

\section{ENTES PÚBLICOS}

\section{A) Derechos fundamentales}

1. Recurso de amparo núm. 2956/1995, interpuesto por la Administración de la Comunidad Autónoma de las Islas Baleares contra Auto de 29 de junio de 1995 de la Sala de lo Contencioso-Administrativo del Tribunal Supremo, que confirmó el requerimiento hecho por la Sala mediante providencia de 2 de marzo de 1995 para que la Administración de la Comunidad Autónoma de las Islas Baleares compareciera en recurso de casación por medio de Procurador. La Administración recurrente en amparo aduce que el requerimiento ignora que la representación y defensa de las CC.AA. corresponde a sus Letrados, y que exigirles que actúen a través de Procurador les hace de peor condición que la Administración del Estado, vulnerando asi los derechos fundamentales a obtener la tutela efectiva de Jueces y Tribunales y a la igualdad ante la ley. El TC deniega el amparo pues, por un lado, la solución de la Sala no puede ser considerada arbitraria, y, por otro lado, los entes públicos no pueden ser considerados como titulares del derecho fundamental a la no discriminación, que sólo es predicable de los españoles. 
«Que las Comunidades Autónomas deban comparecer ante la Sala de lo Contencioso-Administrativo del Tribunal Supremo mediante Procurador de los de Madrid, a tenor del art. 97.1 LJCA, o puedan efectuarlo mediante los Letrados de sus servicios jurídicos, en virtud del art. 447.2 LOPJ, es una cuestión procesal discutible, como acreditan las diversas resoluciones adoptadas por las Secciones que forman la Sala Tercera que menciona la demanda de amparo. Pero cualquiera de las dos soluciones se encuentra fundada en la Ley, sin que en modo alguno pueda ser considerada arbitraria ninguna de ellas.

Sin embargo, desde la perspectiva constitucional, las resoluciones judiciales impugnadas, que exigen que en el recurso de casación la Administración se persone mediante Procurador, no vulneran en modo alguno el art. 24.1 CE» (vid. f.j. 2).

«El razonamiento, fundamentado en el art. $24 \mathrm{CE}$, de la Comunidad Autónoma recurrente se apoya en la premisa de que el Tribunal Supremo debía haber seguido la interpretación de la Ley procesal más favorable para el acceso al recurso de casación, de entre las varias posibles. Pero ese criterio ha sido revisado en nuestra jurisprudencia constitucional a partir de la STC 37/1995, como indica el Ministerio Fiscal.

El núcleo del derecho a la tutela judicial de quienes fueron parte en el proceso judicial previo quedó, pues, satisfecho con la sentencia de fondo dictada en la instancia por el Tribunal Superior de Justicia de Baleares. El derecho al recurso que la Ley haya podido crear, en el presente caso el recurso de casación contencioso-administrativo, debe ser satisfecho cumpliendo los requisitos procesales establecidos por la norma, e interpretados de manera no arbitraria por el Tribunal competente para conocer del recurso, como así ha acontecido.

Por añadidura, en el presente caso la Sala ha ofrecido una oportunidad a la parte para subsanar el requisito de personación omitido. Por lo que tampoco desde esta perspectiva cabe hablar de indefensión» (f.j. 3).

«La alegación del principio de igualdad, del art. $14 \mathrm{CE}$, no puede prosperar.

En primer lugar, nuestra jurisprudencia ha declarado que "los entes públicos no pueden ser considerados como titulares del derecho fundamental a la no discriminación amparado por el art. $14 \mathrm{CE}$, que se refiere a los españoles y no es de aplicación a las personas jurídico-públicas en cuanto tales" (STC 13/1996, fundamento jurídico $3 .^{\circ}$, y AATC $135 / 1985,139 / 1985$ y 106/1988).

No obstante, este Tribunal, no sin ciertos matices y cautelas ..., ha reconocido a las personas jurídicas de Derecho Público el derecho fundamental a la tu- 
RESEÑA DE SENTENCIAS DEL. TRIBUNAL CONSTITUCIONAL ...

tela judicial efectiva en cuanto el ordenamiento les reconoce capacidad para ser parte en un proceso ... y, por ello, tales personas tienen también acceso al recurso de amparo frente a la violación de tal derecho (STC 100/1993, fundamento jurídico $3 .^{\circ}$ ). Pero, como ya se declaró en la STC 100/1993 antes citada, no cabe extender sin más esta doctrina sobre la titularidad de las Entidades públicas del derecho a la tutela judicial efectiva a otros derechos fundamentales susceptibles de ser invocados en amparo. Por consiguiente, la presente alegación de tráto desigual entre la representación procesal de la Administración de la Comunidad Autónoma y la de la Administración General del Estado, carece de relevancia constitucional, pues el principio de igualdad del art. $14 \mathrm{CE}$, cimentado en la dignidad de la persona como fundamento del orden político (art. 10.1 CE) y que está en la base de la noción misma del derecho fundamental, es de todo punto ajeno a la cuestión» (vid. f.j. 4).

Fallo: Denegar el amparo solicitado.

(Sentencia n. ${ }^{\circ}$ 211/1996, de 17 de diciembre. Pleno. BOE de 22 de enero de 1997. A. Rodríguez Bereijo).

\section{B) Prerrogativas}

1. Recurso de amparo núm. 1830/1992, promovido contra la Sentencia de 4 de junio de 1992 de la Sección 4. ${ }^{a}$ de la Sala de lo Contencioso Administrativo del Tribunal Superior de Justicia de Cataluña, que estimó en parte el recurso promovido por la entidad actora contra las Resoluciones del Tribunal Económico Administrativo Regional de Cataluña de 30 de octubre y 27 de noviembre de 1990, sobre retenciones indebidas del Impuesto General sobre el Tráfico de Empresas. La demandante de amparo manifiesta haber sufrido una vulneración de su derecho fundamental a la igualdad ante la ley (art. 14 CE) a través de la resolución judicial impugnada por cuanto la misma le niega el derecho a que se le abone el interés legal de las cantidades líquidas que indebidamente se le retuvieron en concepto de ITE, razonando que tal interés se devenga exclusivamente a partir del transcurso de tres meses desde la notificación de la sentencia, y una vez haya reclamado su abono, todo ello en virtud de lo previsto en el art. 45 de la Ley General Presupuestaria, lo que a juicio de la recurrente supone la negación del derecho al interés legal de las cuotas tributarias indebidamente retenidas para el periodo de tiempo que media desde las fechas de dichas retenciones hasta el dia en que hayan transcurrido los tres meses siguientes a la notificación de dicha Sentencia. El TC estima el amparo. 
«La resolución judicial impugnada ha vulnerado el derecho fundamental de los españoles ante la ley (art. 14 CE) al otorgar al Instituto Catalán de la Salud un trato privilegiado que es constitucionalmente infundado, al carecer de un fundamento objetivo y razonable, con perjuicio en este caso de la entidad demandante de amparo.

El reconocimiento, en efecto, a determinados entes públicos de un estatuto personal en cuanto al devengo de intereses por el impago de sus deudas que, sin atender a la naturaleza de la obligación de que se trate o de la relación jurídica en cuyo seno se haya producido, tenga una extensión tal que prácticamente equivalga a la exoneración del pago de los mismos al condicionarlos al reconocimiento de la deuda por la Administración, vulnera el art. $14 \mathrm{CE}$. En este sentido, debe tenerse en cuenta que lo que aquí se enjuicia no es el otorgamiento a la Hacienda Pública de un plazo de tres meses para proceder al cumplimiento de la sentencia desde la fecha de su notificación, fácilmente justificable por su sometimiento a un estricto régimen presupuestario. Lo que hemos de resolver es si puede admitirse, como compatible con el art. $14 \mathrm{CE}$, un entendimiento del art. 45 LGP, como el contenido en la Sentencia impugnada, conforme al cual la Administración no incurre en mora "ínterin no hayan transcurrido los plazos que establece el art. 45 de la Ley General Presupuestaria, que exige que transcurran tres meses desde la notificación de la Sentencia o reconocimiento de la obligación de pago, y la posterior reclamación del interesado" (fundamento de derecho cuarto).

Este Tribunal ha declarado, desde luego, la constitucionalidad de diversas prerrogativas o de situaciones de superioridad, en general, a las Administraciones Públicas, pero siempre a partir de la existencia de algún bien o principio constitucional cuya preservación justificara su reconocimiento (...) Ahora bien, en el caso que nos ocupa no es posible encontrar ningún bien o principio constitucional cuya protección exija el trato privilegiado otorgado (...) Resulta, pues, que el privilegio derivado de la sentencia recurrida no sólo carece de justificación en orden a satisfacer algún bien constitucionalmente relevante, sino que compromete gravemente otros, toda vez que el particular que sufrió el impago parcial de lo facturado en ejecución de un contrato, para conseguir el pago de lo debido, ha tenido que acudir a los procedimientos administrativo y judicial oportunos para que se declare la ilegalidad de la causa en que se pretendió justificar la minoración del precio, una pretendida retención tributaria, y la consiguiente condena a que se le entreguen tales sumas. Si se le niegan los intereses devengados durante este período, en modo alguno conseguirá la plena satisfacción de su derecho; pues, al tener que acudir al proceso para lograr su reconocimiento el tiempo empleado para ello generará de suyo unos perjuicios que quedarán sin resarcir» (vid. f.j. 5). 
RESEÑA DE SENTENCIAS DEL TRIBUNAL CONSTITUCIONAL ...

Fallo: Estimar parcialmente el recurso de amparo y, en consecuencia:

1. Reconocer a la demandante de amparo el derecho fundamental a la igualdad.

2. Anular parcialmente la Sentencia de 4 de junio de 1992, de la Sección Cuarta de la Sala de lo Contencioso-Administrativo del Tribunal Superior de Justicia de Cataluña, recaída en el Recurso núm. 145/1991, en cuanto al pronunciamiento desestimatorio de la pretensión relativa al reconocimiento de los intereses de demora.

3. Retrotraer las actuaciones, a efectos de posibilitar el concreto pronunciamiento de la Sala respecto de dichos intereses, para que dicte nueva sentencia, que contenga el concreto pronunciamiento de la Sala respecto de los mencionados intereses.

(Sentencia n..$^{\circ}$ 23/1997, de 11 de febrero. Sala Primera. BOE de 14 de marzo de 1997. P. Cruz Villalón).

\section{EMPLEO PÚBLICO}

1. Recurso de inconstitucionalidad núm. 399/1988, interpuesto por el Presidente del Gobierno contra los arts. 3.1 a) y 14 de la Ley del Parlamento de Cataluña 21/1987, de 26 de noviembre, de Incompatibilidades del Personal al Servicio de la Administración de la Generalidad, por cuanto entiende que no respetan, respectivamente, el contenido de los arts. 5 a) y 16.1 de la Ley estatal 53/1984, de Incompatibilidades del Personal al servicio de la Administración, cuya disposición final primera había declarado básicos al amparo del art. 149.1.18. ${ }^{a}$ CE (régimen estatutario de la función pública). El TC declara la inconstitucionalidad del art. 3.1 a) en cuanto omite el requisito establecido en la norma básica respecto a la compatibilidad de actividades con cargos electivos «salvo que perciban retribuciones periódicas por el desempeño de la función».

«Si se comparan ambas normas es evidente, en efecto, que el art. 3.1 a) de la Ley 21/1987 omite el inciso que sí contiene el art. 5 a) de la Ley estatal, a saber, "salvo que perciban retribuciones periódicas por el desempeño de la función". El Abogado del Estado deduce de esta omisión, de un lado, que el citado art. 3.1 a) de la Ley 21/1987, establece un sistema claramente sustitutivo del modelo estatal, cerrando la regulación en este extremo e impidiendo toda suerte de interpretación integradora o conforme de la Ley impugnada y, de otro, que permite resultados prohibidos por el legislador estatal, vgr., que se cobren 
retribuciones periódicas en el Parlamento catalán y sólo dietas e indemnizaciones como funcionario, manteniendo la compatibilidad en contra del claro dictado de la Ley 53/1984, que la excluye siempre que existan retribuciones periódicas parlamentarias. En suma, se aduce, en la Ley básica estatal, cuando se perciben retribuciones periódicas en la Asamblea Legislativa, no cabe nunca la compatibilidad» (vid. f.j. 3).

«La regulación que se contiene en el art. 3.1 a) de la Ley del Parlamento de Cataluña $21 / 1987$, a resultas de tal omisión, es contraria a lo que dispone el art. 5 a) de la Ley estatal 53/1984. Se trata de reglas diferentes. Mientras la norma básica condiciona la compatibilidad, en lo que aquí interesa, a que no se perciban retribuciones periódicas en el desempeño de la función parlamentaria, el art. 3.1 a) de la Ley 21/1987, por el contrario, admite sin más la compatibilidad. En este caso, pues, resulta obligado concluir en igual sentido que en la citada STC 172/1996: el silencio sobre esta condición básica para el sistema de incompatibilidades "no puede calificarse como inocuo, indiferente o neutro... La incorporación íntegra de la norma básica ha de exigirse aquí y ahora por virtud del carácter esencial del requisito omitido. En consecuencia, no siendo posible una interpretación conforme del precepto... resulta clara su invalidez" (cfr. f.j. $3^{\circ}$ ). Por consiguiente, debe declararse la inconstitucionalidad del precepto impugnado, el art. 3.1 a) de la Ley $21 / 1987$, en cuanto al omitir un requisito de incompatibilidad contradice lo dispuesto en la legislación básica» (vid. f.j. 4).

«En atención a la segunda impugnación, conviene recordar cuanto dispone el art. 16.1 de la Ley estatal 53/1984:

"No podrá autorizarse o reconocerse compatibilidad alguna al personal que desempeñe puestos que comporten la percepción de complementos específicos o concepto equiparable, y al retribuido por arancel".

Por su parte, el art. 14 de la Ley del Parlamento de Cataluña, 21/1987, establece que:

"No podrá autorizarse ni reconocerse compatibilidad al personal que ocupe los puestos de trabajo que comporten la percepción de un complemento específico por el factor de incompatibilidad o por concepto equiparable".

A resultas de cuanto antecede ( $c f r . \mathrm{f} . \mathrm{j} .4^{\circ} .^{\circ}$, debe comenzarse por afirmar el carácter básico del art. 16.1 de la Ley 53/1984 en virtud de los mismos argumentos esgrimidos en relación con el art. 5 a). Que la materia regulada en el indicado precepto se acomoda al concepto de lo básico, es algo que además este Tribunal ha tenido ocasión de explicitar en la STC 172/1996 (f.j. 3. ${ }^{\circ}$ ). Con todo, debe tenerse presente que a la luz de esta sentencia lo que ha de conside- 
RESEÑA DE SENTENCLAS DEL TRIBUNAL CONSTTTUCIONAL...

rarse básico, de acuerdo con lo que dispone el art. 16.1, “es la prohibición de simultanear dos actividades en el sector privado y en el público cuando se perciban retribuciones complementarias por especial dedicación al puesto de trabajo en las Administraciones públicas" (cfr. STC 172/1996, f. j. 3.º) (f.j. 5).

Fallo: Estimar parcialmente el recurso interpuesto por el Gobierno de la Nación y, en su virtud,

1. Declarar que es inconstitucional el art. 3.1 a) de la Ley del Parlamento de Cataluña, 21/1987, de 26 de noviembre, de Incompatibilidades del Personal al Servicio de la Administración de la Generalidad, en cuanto omite el requisito establecido en la norma básica.

2. Desestimarlo en todo lo demás.

(Sentencia n. 73/1997, de 11 de abril. Pleno. BOE de 13 de mayo de 1997. E. Ruiz Vadillo).

2. Recurso de amparo núm. 2099/1994, contra la Sentencia de la Sección Primera de la Sala de lo Contencioso-Administrativo del Tribunal Superior de Justicia de Galicia, de 30 de abril de 1994, que confirmó la denegación de la solicitud de reconocimiento del nivel 26, realizada por los funcionarios de la Consellería de Agricultura, Ganadería y Montes de la Xunta de Galicia. Los recurrentes en amparo alegan discriminación, por entender que una recta interpretación del Acuerdo de la Xunta estableciendo la clasificación y valoración de los puestos de trabajo de la Administración autonómica, impone primar como criterio rector de la asignación del nivel controvertido la realización de funciones facultativas por técnicos superiores, lo que desplazaría la referencia a la específica titulación de Arquitecto e Ingeniero. El TC deniega el amparo.

«La queja de los recurrentes se basa en una supuesta lesión del principio de igualdad por el no reconocimiento a los interesados, funcionarios, de carrera e interinos, integrados en la Escala de Técnicos Facultativos Superiores, grupo A, de la Xunta de Galicia, y adscritos a su Consellería de Agricultura, Ganadería y Montes, del nivel 26 , que, en su momento, y de conformidad con los Acuerdos del Consejo de la Xunta de 1 de junio y 14 de septiembre de 1989, habían solicitado. Denegación, recordemos, que traía causa de la no posesión por aquéllos de la titulación requerida por el Acuerdo últimamente aludido (esto es, la de Arquitectos superiores o Ingenieros superiores) y que es combatida por los demandantes por entender que una recta interpretación de los citados Acuerdos, que habían establecido la clasificacion y valoración de los puestos 
de trabajo de la Administración autonómica, impone alzaprimar el, en su inteligencia, criterio rector de la asignación del controvertido nivel, el ejercicio por técnicos superiores de funciones facultativas; de suerte que la mención entre paréntesis) a las titulaciones meritadas no reviste sino un mero carácter ejemplificador» (vid. f.j. 19).

«Pues bien, la elucidación de la cuestión propuesta, que abordamos seguidamente, exige tener en cuenta, a modo de recapitulación, las siguientes premisas: a) aun cuando el principio de igualdad ex art. 23.2 CE - precepto que se erige, ante la no constancia de alguno de los factores de discriminación proscritos por el art. $14 \mathrm{CE}$, en parámetro decisor de aquélla- opera tanto en el momento del acceso como en el ulterior del desempeño de las funciones públicas, aquél actúa con diferente "rigor e intensidad" en uno y en otro, de suerte que en este segundo tienen cabida otros distintos "en atención a una mayor eficacia del servicio o a la prosecución de otros bienes constitucionalmente protegidos" (STC 200/1991, f.j. $2 .^{\circ}$, con remisión a la STC 192/1991, f.j. 4. ${ }^{\circ}$ ); b) no nos corresponde verificar la adecuación del criterio que se funda en la titulación para asignar los correspondientes niveles [arts. 16 y 20.1 , c) de la Ley $30 / 1984$, a la que se anuda, por otro lado, la percepción del complemento de destino ex art. 23.3 , a) de la Ley 30/1984] puesto que dicho criterio, en sí mismo, no resulta manifiestamente impertinente en atención a su finalidad» (f.j. 6).

«Por lo expuesto, no cabe entender que la reserva en exclusiva (insistimos: abstracción hecha de su corrección en el plano de la convencionalmente denominada legalidad ordinaria) a los funcionarios en que concurra la titulación de Ingenieros o Arquitectos del reconocimiento de determinado nivel, y la interpretación administrativa y judicial producida al efecto, de la que, en modo alguno, cabe predicar la asunción de criterios personales no amparados en la oportuna normativa, con exclusión de los demás cuyos Cuerpos, Escalas, Clases o Categorías se hallen clasificados, igualmente, en el grupo A, contrarien las exigencias del principio de igualdad, al menos en la vertiente que da acceso al recurso de amparo» (f.j. 7).

Fallo: Denegar el amparo solicitado.

(Sentencia n. ${ }^{\circ}$ 96/1997, de 19 de mayo. Sala Segunda. BOE de 9 de junio de 1997. J. D. González Campos).

3. Recurso de inconstitucionalidad núm. 544/1988, promovido por el Gobierno de la Nación contra los artículos 12, 73.1, a) y 13.1, b), en cuanto al exceso que en los mismos se prevé respecto de las magnitudes establecidas en la Ley 33/1987, de Presupuestos del Estado para 1988, así como contra 
RESEÑA DE SENTENCIAS DEL. TRIBUNAL CONSTTTUCIONAL ..

los párrafos segundo y tercero del artículo 13.1, d) de la Ley de la Asamblea de Madrid 4/1987, de 23 de diciembre, de Presupuestos Generales de la Comunidad de Madrid para 1988. El recurrente entiende que en dichos preceptos se infringen los arts. 149.1.13. ${ }^{a}$ y 18.a y 156.1 CE puesto que se establecen incrementos retributivos para los funcionarios de la Comunidad de Madrid que superan los límites fijados por el Estado, vulnerando asi el principio de coordinación de la Hacienda de la Comunidad Autónoma con la Hacienda Estatal, asi como la competencia del Estado sobre las bases y coordinación de la planificación general de la actividad económi$c a$, y sobre las bases del régimen estatutario de los funcionarios públicos. El TC estima parcialmente el recurso y declara la inconstitucionalidad y nulidad de los artículos 12, 13.1, a), y 13.1, b) de la citada Ley, y la constitucionalidad del artículo 13.1, d), párrafos $2 .^{\circ}$ y $3 .^{\circ}$, de la misma Ley si se interpreta en los términos contenidos en el fundamento jurídico $4 .^{\circ}$ de esta sentencia.

«La primera de las cuestiones planteadas en este proceso estriba en dilucidar si el art. 12 de la Ley de Presupuestos de la Comunidad de Madrid para 1988 ha vulnerado el orden constitucional de competencias, toda vez que, ignorando el tope máximo del $4 \%$ fijado por la Ley 33/1987, de Presupuestos Generales del Estado para 1988 (art. 28.1), establece en su primer párrafo que "el incremento del conjunto de las retribuciones íntegras del personal en activo de la Comunidad y sus Organismos Autónomos no sometido a la legislación laboral, aplicadas en las cuantías y de acuerdo con los regímenes retributivos vigentes en 1987, será del 5\% por todos los conceptos..... Sostiene la parte actora que el incumplimiento por parte de la Comunidad Autónoma de la restricción retributiva establecida por el Estado entraña, de una parte, la vulneración del art. 149.1.13. ${ }^{\mathrm{a}} \mathrm{CE}$, ya que dicha medida, al pretender contener la expansión de uno de los componentes esenciales del gasto público, se ha dictado en ejercicio de su competencia sobre las "bases y coordinación de la planificación general de la actividad económica"; y, de otro lado, alega que infringe, asimismo, el art. 156.1 CE, dado que la exigencia de coordinación con la Hacienda estatal constituye un límite de la autonomía financiera de las Comunidades Autónomas.

La cuestión así suscitada es prácticamente idéntica a la que resolvimos en la reciente STC 171/1996, esencialmente en su fundamento jurídico 2. Pues bien, como entonces dijimos y ahora hemos de reiterar, la imposición de este tipo de topes máximos por parte del Estado halla justificación tanto en el título competencial contenido en el art. 149.1.13. ${ }^{\mathrm{a}} \mathrm{CE}$ como en el principio de coordinación, que opera como límite de la autonomía financiera de las CC.AA. (art. 156.1 CE) con el alcance previsto en el art. 2.1, b) LOFCA (SSTC 63/1986, 96/1990 y 237/1992). 
Consiguientemente, puesto que la norma autonómica recurrida contradice abiertamente lo dispuesto en una medida económica general de carácter presupuestario dirigida a contener la expansión relativa de uno de los componentes del gasto público y establecida a través de la Ley de Presupuestos Generales del Estado, no cabe sino declarar, como igualmente hicimos en la STC 171/1996, la inconstitucionalidad de la misma por vulnerar el art. 149.1.13. ${ }^{\mathrm{a}} \mathrm{CE}$ » (vid. f.j. 1).

«El Abogado del Estado, en segundo término, entiende que el art. 13.1, a) de la Ley autonómica impugnada incurre en inconstitucionalidad al vulnerar el art. 149.1.18. ${ }^{\mathrm{a}} \mathrm{CE}$, que reserva al Estado las bases del régimen estatutario de los funcionarios. La infracción se habría producido porque, al fijar dicha disposición para cada grupo, unos sueldos y trienios superiores a los establecidos en la Ley de Presupuestos del Estado, incumple así lo preceptuado en una norma de carácter básico, cual es la contenida en el primer inciso del art. 24.1 de la Ley 30/1984, de Medidas para la Reforma de la Función Pública, que reza así:

"Las cuantías de las retribuciones básicas serán iguales en todas las Administraciones Públicas para cada uno de los grupos en que se clasifican los cuerpos, escalas, categorías o clases de funcionarios" (...)

Pues bien, en lo que atañe al art. 24.1 de la Ley 30/1984, pocas dudas hay que albergar acerca de que se trata de una norma materialmente básica. Como tantas veces ha reiterado este Tribunal, una norma merece tal calificativo cuando garantiza en todo el Estado un común denominador normativo dirigido a asegurar, de manera unitaria y en condiciones de igualdad, los intereses generales; regulación normativa uniforme que, no obstante, debe permitir que cada Comunidad Autónoma introduzca, en persecución de sus propios intereses, las peculiaridades que estime pertinentes dentro del marco competencial que en la materia dibuje el bloque de la constitucionalidad ... A la luz de esta línea jurisprudencial, resulta palmaria la adecuación al orden constitucional de competencias de un precepto que determina la nivelación de la cuantía de las retribuciones básicas en todas las Administraciones Públicas (esto es, sueldos, trienios y pagas extraordinarias, según el art. 23.2 de la Ley 30/1984), pues no persigue otro objetivo que lograr una mínima y fundamental homogeneidad en un aspecto sustancial del régimen funcionarial, cual es el atinente a los derechos económicos. De hecho, en relación precisamente con el art. 24 de la Ley 30/1984, ya en la STC 63/1986, tuvimos la oportunidad de señalar que, indudablemente, entre las bases del régimen estatutario de los funcionarios a que se refiere el art. 149.1.18. ${ }^{\text {a }} \mathrm{CE}$ "cabe incluir previsiones relativas a las retribuciones de los funcionarios, comunes a todas las Administraciones Públicas, lo que, a su vez, hallaría fundamento en los principios constitucionales de igualdad y solidaridad" (fundamento jurídico 11; y, en la misma línea, SSTC 96/1990, fundamento jurídico 3 , y 237/1992, fundamento jurídico 4). 
RESEÑA DE SENTENCIAS DEL TRIBUNAL CONSTITUCIONAL ..

Por lo demás, tampoco se aprecia que la norma estatal básica que ha sido cuestionada por la Comunidad Autónoma sea tan incisiva que menoscabe, anule o no deje margen al ejercicio de la competencia autonómica a fin de que ésta adopte una política retributiva propia respecto de sus funcionarios (...)

Por consiguiente, sentado lo anterior, y siendo evidente que el art.13.1, a) de la Ley autonómica recurrida establece unas retribuciones en concepto de sueldo y trienios superiores a las fijadas en el art. 31.1 , a) de la Ley de Presupuestos Generales del Estado, resulta no menos obvio que, con ello, se ha ignorado la exigencia básica contenida en el primer inciso del art. 24.1 de la Ley 30/1984, incurriendo así la disposición recurrida en inconstitucionalidad» (vid. f.j. 2).

«El art. 13.1, b) de la Ley autonómica recurrida es impugnado, en primer término, desde la misma perspectiva cuantitativa en que se ha fundado el recurso dirigido contra el art. 13.1, a), es decir, porque puestos en conexión ambos preceptos, la cuantía de las pagas extraordinarias objeto de regulación en el primero de ellos excede de la que, por referencia a sueldo y trienios, ha fijado el art. 31.1, a) de la Ley de Presupuestos Generales del Estado para 1988.

Mas en este concreto aspecto la vulneración del orden competencial, por infracción de la exigencia básica contenida en el art. 24.1 de la Ley 30/1984, en cuanto referida a las pagas extraordinarias como integrantes de las retribuciones básicas no es imputable al art.13.1, b) en sí mismo considerado, sino a la norma a que este precepto reenvía, es decir, al art. 13.1, a) de la misma Ley autonómica, cuya inconstitucionalidad ya hemos declarado.

En consecuencia, atendiendo al primer motivo impugnatorio aducido contra el precepto de la Ley autonómica que ahora nos ocupa (art. $13.1 \mathrm{~b}$, relativo a la cuantía de las pagas extraordinarias), no puede acogerse la pretensión de inconstitucionalidad ejercitada por el Abogado del Estado.

Por lo que concierne, en cambio, al segundo motivo en que fundamenta su pretensión la representación del Estado, es decir, la vulneración del orden constitucional de distribución de competencias, por infracción del mandato contenido en el art. 24.2 de la Ley 30/1984, ha de estimarse la pretensión de declaración de inconstitucionalidad del art. 13.1, b) de la Ley 4/1987, de Madrid.

En efecto, el citado art. 24.2, precepto materialmente básico por cuanto que, junto a otras finalidades, obedece al designio de hacer efectivo el mandato de igualdad para todas las Administraciones Públicas de la cuantía de las retribuciones básicas, establece que la concreta cuantía de éstas, y por tanto, de las pagas extraordinarias que, como concepto retributivo específico forma parte de 
aquéllas, deberá figurar en los Presupuestos de las Administraciones Públicas. Pues bien, este mandato contenido en la norma básica estatal resulta incumplido por la Comunidad Autónoma de Madrid, cuando el art. 13.1, b) de la Ley de Presupuestos impugnada dispone que: "las pagas extraordinarias se percibirán de acuerdo con lo dispuesto en el art. 73, c) de la Ley 1/1986", precepto éste de la Ley reguladora de la Función Pública autonómica, a cuyo tenor, las pagas extraordinarias serán dos al año, por un importe mínimo cada una de ellas de una mensualidad del sueldo y trienios. Esta remisión al precepto material o sustantivo de la normativa autonómica sobre la función pública, referido a un importe mínimo, deja sin precisar el concreto importe o cuantía de las pagas extraordinarias, como concepto retributivo que integran las retribuciones básicas, cuya concreta determinación cuantitativa ha de verse adecuadamente reflejada en la correspondiente Ley de Presupuestos.

Se impone, por ello, declarar que vulnera el orden constitucional de competencias el art. 13.1, b) de la Ley autonómica, al ser contrario a la norma básica del Estado contenida en el art. 24.2 de la Ley 30/1984» (f.j. 3).

Fallo: Estimar el recurso de inconstitucionalidad y, en consecuencia:

1. Declarar la inconstitucionalidad y consiguiente nulidad de los arts. 12, 13.1, a) y 13.1, b) de la Ley de la Asamblea de Madrid 4/1987, de 23 de diciembre, de Presupuestos Generales de la Comunidad de Madrid para 1988.

2. Declarar que el art. 13.1, d), párrafos segundo y tercero de la citada Ley no es inconstitucional si se interpreta en los términos contenidos en el fundamento jurídico 4 de esta Sentencia.

(Sentencia n. ${ }^{\circ}$ 103/1997, de 22 de mayo. Pleno. BOE de 9 de junio de 1997. E. Ruiz Vadillo).

\section{JURISDICCIÓN CONTENCIOSO-ADMINISTRATIVA}

1. Recurso de amparo núm. 174/1995, promovido contra la Sentencia de la Sala de lo Contencioso-Administrativo del Tribunal Superior de Justicia de Galicia, de I de diciembre de 1994, sobre sanciones de multa por infracciones en materia de protección de recursos marítimo pesqueros. El TC otorga el amparo porque si bien entiende que no se ha vulnerado el derecho a la presunción de inocencia del actor, sin embargo considera que si ha resultado vulnerado su derecho a utilizar los medios de prueba pertinentes para su defensa, reconocido por el art. 24.2 CE. 
RESEÑA DE SENTENCLAS DEL TRIBUNAL CONSTTTUCIONAL ...

«Es de resaltar nuevamente que el actor negaba frontalmente los hechos sostenidos por la Administración y que habían dado lugar a la sanción administrativa. Y que la Sala no es que denegara específicos medios de prueba por considerarlos impertinentes, sino que negó sin más la apertura de período probatorio en el proceso contencioso-administrativo. Con ello impidió totalmente el ejercicio del derecho a la prueba por parte de la defensa, que se lleva a cabo en el seno del proceso judicial, y que resultaba esencial para poder acreditar los hechos ofrecidos por el actor en su descargo, y así desvirtuar la verosimilitud de las pruebas de cargo presentadas por la Administración (STC 94/1992).

El recibimiento a prueba en el proceso administrativo procede cuando existe disparidad sobre los hechos objeto de controversia y éstos son de trascendencia para la resolución del litigio, conforme determina el art. $74.3 \mathrm{LJ}$, requisitos que concurren plenamente en el caso. Siendo ello así, solamente a través de la apertura del período probatorio podía "el Juez del contencioso formar su convicción sobre la base de una valoración o apreciación razonada de las pruebas practicadas" (STC 76/1990, fundamento jurídico $8 .^{\circ} \mathrm{B}$ ), tal y como exige el art. 24.2 CE» (vid. f.j. 8).

«Frente a esta conclusión no resultan convincentes las razones ofrecidas para justificar la denegación de la fase probatoria del proceso.

La verosimilitud, detalle y aún contundencia del acta de infracción serán o podrán ser aspectos relevantes en el momento posterior de valorar las pruebas pertinentes en el proceso, pero no en el anterior, de decidir acerca de la apertura de período probatorio. El riesgo de que alguna de las partes incurra en pruebas abusivas o excesivas no puede conjurarse denegando el recibimiento a prueba del proceso, sino rechazando de manera motivada y razonada los concretos medios de prueba propuestos que puedan resultar impertinentes o intrascendentes.

Carecen, pues, de toda relevancia las alusiones a la "pertinencia" de las pruebas de que intentaba valerse el acto. Al no recibirse a prueba el proceso contencioso-administrativo, el recurrente no tuvo ocasión de proponer la práctica de aquellas que a su derecho conviniera, ni la Sala se pronunció acerca de la relevancia o utilidad de ninguna de ellas (STC 94/1992). Las alusiones que en la sentencia aquí impugnada se hacen a los documentos aportados por el denunciado en el expediente administrativo no son convincentes, pues, como es sabido, la jurisdicción contencioso-administrativa no es una segunda instancia, sino que "ante ella, por el contrario, se sigue un auténtico juicio o proceso entre partes" (exposición de motivos de la LJCA), por lo que las pruebas a practicar en el proceso son independientes de los actos de instrucción que hayan 
podido llevarse a cabo en el previo procedimiento administrativo (STC 138/1990)» (f.j. 9).

«La conclusión alcanzada debe llevar derechamente al otorgamiento del amparo y a la anulación de los autos que denegaron el recibimiento a prueba en el proceso contencioso-administrativo, así como de la sentencia dictada con posterioridad, exclusivamente porque fue pronunciada tras un proceso en el que se había vulnerado el derecho de la defensa a usar los medios de prueba pertinentes (STC 94/1992, fundamento jurídico 5. ${ }^{\circ}$ ). Este derecho fundamental ha de ser restablecido mediante la apertura del período probatorio, apertura que no limita en modo alguno la potestad judicial para apreciar la pertinencia de los medios de prueba que proponga el ahora recurrente en su defensa, ni menos aún la final valoración de los hechos, que corresponde de manera exclusiva al órgano judicial (STC 76/1990, fundamento jurídico 8. ${ }^{\circ}$ B)» (f.j. 10).

Fallo: Otorgar parcialmente el amparo solicitado y, en consecuencia:

1. Reconocer el derecho fundamental del recurrente a utilizar los medios de prueba para su defensa (art. 24.2 CE).

2. Restablecerle en la integridad de su derecho mediante la anulación de los Autos dictados por el Tribunal Superior de Justicia de Galicia con fecha de 18 de junio y 7 de septiembre de 1993, así como la Sentencia de 1 de diciembre de 1994, pronunciada en autos del recurso contencioso-administrativo nứm. 5101/1992.

3. Retrotraer las actuaciones judiciales al momento procesal de la apertura del juicio a prueba.

(Sentencia $n^{\circ} 14 / 1997$, de 28 de enero. Sala Primera. BOE de 26 de febrero de 1997. E. Ruiz Vadillo).

2. Recurso de amparo núm. 3390/1994, promovido contra los Autos emitidos por el Tribunal Superior de Justicia de Galicia (Sala de lo Contencioso-Administrativo, Sección Segunda), de 17 de junio y 23 de septiembre de 1994, que declararon caducado el recurso interpuesto por la empresa demandante de amparo contra la Resolución del Alcalde de O Grove que le había impuesto una multa por infracción urbanística. La empresa recurrente en amparo alega que la declaración de caducidad, por formalista y desproporcionada, vulnera su derecho de acceso a la jurisdicción. El TC otorga el amparo. 
RESEÑA DE SENTENCIAS DEL. TRIBUNAL CONSTTTUCIONAL ...

«La entidad demandante de amparo, "Xunqueiriña, S.L.", se encuentra íntimamente ligada con otra, "Outón y Fernández, S.L.", integrada por los mismos socios. Ambas fueron multadas por el Ayuntamiento de O Grove por llevar a cabo una obra con infracción de la legalidad urbanística, aquélla como promotora de la obra y ésta como constructora. Las dos sanciones fueron impuestas mediante una única Resolución, dictada por el Alcalde tras tramitar un expediente administrativo conjunto para todos los implicados en la construcción del sobrealzado de la casa.

Cada una de las sociedades mercantiles interpuso por separado recurso contencioso-administrativo ante el Tribunal Superior de Justicia, que fueron registrados por la Sala de lo Contencioso-Administrativo bajo dos números diferentes y sucesivos (el núm. 4419/1994, para el presentado por "Outón y Fernández", y el núm. 4420/1994, para el promovido por "Xunqueiriña"). En ambos recursos, las sociedades se encontraban representadas por la misma Procuradora y defendidas por el mismo Abogado.

Dichos profesionales, a quienes se les había entregado el expediente administrativo remitido por el Ayuntamiento, formularon un escrito de demanda común a ambos procesos, en nombre de las dos sociedades. Sin embargo, como advierte el Fiscal ante este Tribunal, ni habían pedido la acumulación de autos, que no había sido acordada por la Sala, ni tampoco aportaron copia de la demanda común, para su incorporación a los autos de los dos procesos. La Sección Segunda de la Sala de lo Contencioso-Administrativo del Tribunal Superior de Justicia de Galicia acordó tener por presentada la demanda en el primero de los recursos, el núm. 4419/1994, y declaró caducado el segundo por no haber presentado demanda dentro del plazo establecido, mediante las resoluciones impugnadas en esta sede constitucional» (f.j. 1).

«El examen del fondo de la cuestión suscitada por el presente recurso, el derecho fundamental a la tutela judicial efectiva y sin indefensión, lleva al otorgamiento del amparo solicitado.

En efecto, según nuestra reiterada jurisprudencia, el núcleo de ese derecho constitucional consiste en el acceso a la jurisdicción: Que un Tribunal resuelva en el fondo la controversia de derechos e intereses legítimos ante él planteada, salvo que se lo impida una razón fundada en un precepto expreso de una Ley, que a su vez sea respetuoso con el contenido esencial del derecho fundamental» (vid. f.j. 3).

«Los defectos cometidos por la representación procesal del actor son merecedores de reproche. Pero no pueden conducir a que se deniegue, sin más, una sentencia sobre el fondo del asunto. El carácter esencial que tiene el derecho de 
acceso a la justicia debe llevar a permitir la continuación del proceso, salvo que el actor, tras el pertinente requerimiento, persistiese en su actuación pasiva o errónea.

Desde la perspectiva constitucional, es indiferente el medio procesal que la Sala de lo Contencioso-Administrativo pudo y puede seguir para llegar a resolver el fondo de las pretensiones ejercitadas por la empresa demandante frente al Ayuntamiento demandado. Lo decisivo, desde el punto de vista del derecho fundamental, es que se preste una tutela judicial efectiva, siendo indiferentes los medios procesales que emplee el Tribunal competente para hacerlo» (vid. f.j. 4).

«Es de resaltar que la peculiar actuación de la entidad recurrente en ningún momento indujo a error o perjudicó a la contraparte. El Ayuntamiento demandado se personó, de hecho, mediante el mismo escrito "en los recursos contencioso-administrativos núms. 4420/1994 y 4419/1994 interpuestos por "Xunqueiriña, S.L.", y "Outón y Fernández, S.L.", contra mi representado". Por consiguiente, es claro que la caducidad decretada por el Tribunal Contencioso-Administrativo impuso una consecuencia desproporcionada al defecto cometido por la recurrente, perfectamente subsanable sin perjuicio para la contraparte, y que no justifica la pérdida definitiva e irremediable de su derecho a una resolución sobre el fondo del litigio» (f.j. 5).

Fallo: Otorgar el amparo solicitado y, en consecuencia:

1. Reconocer el derecho de la recurrente a la tutela judicial efectiva.

2. Anular los Autos dictados por el Tribunal Superior de Justicia de Galicia (Sala de lo Contencioso-Administrativo, Sección Segunda), de 17 de junio y 23 de septiembre de 1994, en el proceso registrado con el núm. 4420/1994.

3. Restablecer a la recurrente en su derecho fundamental, retrotrayendo las actuaciones judiciales al momento procesal oportuno, para que la Sección Segunda de la Sala de lo Contencioso-Administrativo del Tribunal Superior de Justicia de Galicia proceda, de conformidad con el art. 24.1 CE, a continuar la sustanciación del recurso contencioso-administrativo.

(Sentencia n. ${ }^{\circ}$ 36/1997, de 25 de febrero. Sala Primera. BOE de 1 de abril de 1997. A. Rodríguez Bereijo).

3. Recurso de amparo núm. $2545 / 1994$, interpuesto contra la Sentencia de la Sala de lo Contencioso-Administrativo del Tribunal Superior de Justicia de Andalucia con sede en Sevilla de fecha 22 de abril de 1994, sobre impug- 
RESEÑA DE SENTENCIAS DEL TRIBUNAL CONSTTTUCIONAL ..

nación de liquidación tributaria en relación con el Impuesto sobre Bienes Inmuebles. La recurrente en amparo alega la violación del art. $24.1 C E$, al haber equivocado el órgano judicial el objeto del recurso, dejando sin respuesta alguna la cuestión ante él planteada que no era otra que la impugnación de la liquidación tributaria. El TC otorga el amparo.

«Constituye el objeto de este recurso de amparo, la sentencia dictada por la Sala de lo Contencioso-Administrativo del Tribunal Superior de Justicia de Andalucía, que desestimó el recurso interpuesto contra la liquidación tributaria que en concepto de Impuesto sobre Bienes Inmuebles correspondiente al ejercicio de 1990, había girado el Ayuntamiento de San Fernando (Cádiz).

Por la recurrente se alega la violación del art. 24.1 CE, al haber equivocado el órgano judicial el objeto del recurso, dejando sin respuesta alguna la cuestión ante él planteada que no era otra que la impugnación de la liquidación tributaria.

Tanto el Abogado del Estado, como el Ministerio Fiscal se adhirieron a la petición de amparo, si bien el Fiscal estimó que el reproche que debía formularse a la sentencia impugnada era el de incongruencia omisiva y extra petita, mientras que la defensa del Estado lo circunscribió solamente a esta última categoríai (f.j. 1).

«Concurre en este supuesto la modalidad de incongruencia que puede calificarse como de "omisiva", ya que, en todo caso, la cuestión que verdaderamente fue planteada, esto es, la impugnación del acuerdo del Ayuntamiento de San Fernando por la que se practicó una liquidación por el Impuesto sobre Bienes Inmuebles, no fue objeto de análisis en la fundamentación jurídica de la sentencia combatida, ni por lo tanto se obtuvo una respuesta por parte del órgano judicial» (vid. f.j. 3).

«En atención a lo expuesto, procede dictar una sentencia estimatoria, en la que, otorgando el amparo, se ordene retrotraer las actuaciones para que la Sala de lo Contencioso-Administrativo del Tribunal Superior de Justicia de Andalucía con sede en Sevilla, dicte una nueva sentencia, esta vez pronunciándose sobre el ajuste a Derecho del acto verdaderamente impugnado en el proceso al que se refieren estas actuaciones» (f.j. 4).

Fallo: Otorgar el amparo y, en su virtud:

1. Reconocer el derecho a la tutela judicial efectiva de la recurrente. 
REALA 274-275 (MAYO-DICIEMBRE. 1997)

2. Declarar la nulidad de la Sentencia de la Sala de lo Contencioso-Administrativo del Tribunal Superior de Justicia de Andalucía con sede en Sevilla de 22 de abril de 1994, en el Auto núm. 5522/1991 sobre impugnación de liquidación tributaria.

3. Ordenar la retroacción de las actuaciones para que la Sala de lo Contencioso-Administrativo del Tribunal Superior de Justicia de Andalucía dicte, con libertad de criterio, una nueva sentencia en la que se resuelva sobre la pretensión impugnatoria del acto administrativo objeto de recurso.

(Sentencia n. ${ }^{\circ}$ 47/1997, de 11 de marzo. Sala Primera. BOE de 11 de abril de 1997. E. Ruiz Vadillo).

4. Recurso de amparo núm. 98/1995, promovido pór la Confederación Sindical de CC.OO., contra Sentencia de 14 de diciembre de 1994 de la Sección Tercera de la Sala de lo Contencioso-Administrativo del Tribunal Superior de Justicia de la Comunidad Valenciana sobre Resolución de la Comisión de Gobierno del Ayuntamiento de Carcaixent, de 9 de julio de 1992, que declara la inadmisibilidad de recurso contencioso por falta de legitimación del Sindicato recurrente, al no haber interpuesto recurso de reposición previo. El Sindicato demandante de amparo aduce que el órgano judicial debió entender que el firmante del recurso de reposición previo no lo hacía a título personal, sino como representante sindical. El TC otorga el amparo.

«La sentencia recurrida declaró la inadmisibilidad del mismo por falta de legitimación del Sindicato recurrente, fundándose para ello en que el mismo no había intervenido en el procedimiento administrativo previo ni había interpuesto el recurso de reposición (18 de junio de 1992) contra el acto municipal impugnado, que en aquel momento (previo a la vigencia de la Ley 30/1992, de 26 de noviembre, de Régimen Jurídico de las Administraciones Públicas y del Procedimiento Administrativo Común) era exigible. Argumentándose, además, que dicho recurso se había interpuesto ... a título particular y sin constancia de que lo hiciese como miembro o representante de Comisiones Obreras. Mas, como alega el Fiscal, aquél realmente fue admitido a una persona que era Secretario general de Comisiones Obreras y, no habiendo intervenido a título personal lo hizo con aquel carácter.

Pero, sobre todo, ningún argumento que no fuese el señalado se enderezaba a discernir la legitimación al Sindicato para la interposición del recurso contencioso-administrativo, el cual obviamente había de tener por objeto, no sólo el acto desestimatorio de la reposición, sino la decisión municipal confirmada por 
RESEÑA DE SENTENCLAS DEL TRIBUNAL CONSTITUCIONAL ...

éste a tenor del art. 55 de la Ley de la Jurisdicción Contencioso-Administrativa entonces vigente. En consecuencia, la falta de legitimación se hizo derivar por la Sala sentenciadora exclusivamente del citado hecho de que el Sindicato no hubiera interpuesto el previo recurso de reposición, a tenor del art. 52.1 de la propia Ley de dicha Jurisdicción.

Parece, por tanto, haberse confundido la legitimación para intervenir en el procedimiento administrativo con la exigible para la interposición del proceso judicial frente a los actos administrativos que, a tenor del art. 28 a) de la citada Ley jurisdiccional, ostenta quien tuviere interés directo en la declaración de no ser el acto impugnado conforme a Derecho. Y ha de tenerse en cuenta que esta legitimación procesal no deriva de haber intervenido en el procedimiento administrativo sino de que el recurrente ostente dicho interés. El recurso de reposición se configuraba en la Ley de aquella jurisdicción como un requisito previo a la interposición del contencioso-administrativo $\mathrm{y}$, además, subsanable a tenor del art. 129.3 de la propia Ley, conclusión a la que incluso dio la jurisprudencia una interpretación extensiva en virtud del principio de la interpretación más favorable al examen de fondo de las pretensiones, rector de aquel proceso.

De ahí que la interpretación acorde con el art. 24.1 de la Constitución difiera manifiestamente de la adoptada en la sentencia puesto que, si bien una declaración de inadmisibilidad por motivo legalmente previsto no vulneraría el derecho de acceso a la jurisdicción, sí lo conculca cuando se ha aplicado al mismo una interpretación no acorde con el referido principio general favorable al examen del fondo de la pretensión, coincidente por otra parte con el que informa la aplicación del art. 24.1 CE. Así, según dijimos en la STC 217/1994 (en relación con otro presupuesto del proceso "Se vulnera el mencionado derecho [de acceso a la jurisdicción] cuando el órgano judicial injustificadamente por acción u omisión, cierra a una persona la posibilidad de suplir, por los medios que el ordenamiento pone a su disposición, su falta de postulación procesal"). Lo cual es claramente el caso cuando, como aquí, lejos de aplicar el precepto legal que establecía la subsanación de la falta del recurso de reposición previo por parte de la recurrente, se estimó su falta de legitimación para el proceso sin examinar si en ella concurría un interés directo como la Ley exige.

Procede, en consecuencia, la estimación del recurso» (vid. f.j. 3).

Fallo: Estimar el presente recurso de amparo y, en su virtud:

1. Reconocer al Sindicato Comisiones Obreras su derecho a la tutela judicial efectiva. 
2. Anular la Sentencia de la Sección Tercera de la Sala de lo Contencioso-Administrativo del Tribunal Superior de Justicia de la Comunidad Valenciana, de 14 de diciembre de 1994.

3. Reponer las actuaciones judiciales al momento anterior a la sentencia para que pueda acordarse lo procedente.

(Sentencia n. 55/1997, de 17 de marzo. Sala Segunda. BOE de 17 de abril de 1997. J. Gabaldón López. Voto particular formulado por F. García-Mon y González-Regueral).

5. Recurso de amparo núm. 377/1995, promovido contra Auto de 10 de enero de 1995 de la Sala de lo Contencioso-Administrativo del Tribunal Superior de Justicia de las Islas Baleares, desestimatorio del recurso de súplica contra Providencia de 20 de diciembre de 1994, por la que se acordó el archivo de las actuaciones por incumplimiento del trámite de comunicación previa a la Administración exigido por el art. 110.3 de la Ley 30/1992, e inadmitiendo a trámite el recurso contencioso-administrativo interpuesto contra Resolución de 25 de enero de 1994, del Ayuntamiento de Mahón. El recurrente en amparo entiende que el órgano judicial hace una interpretación rigurosa y literal de un requisito de forma subsanable que vulnera el derecho fundamental a obtener la tutela efectiva de Jueces $y$ Tribunales. El TC otorga el amparo.

«La cuestión que se plantea en el presente recurso de amparo ha sido resuelta en la Sentencia del Pleno de este Tribunal (STC 76/1996, cuya doctrina ha sido reiterada en posteriores Sentencias de Sala... En la mencionada Sentencia del Pleno declaramos la constitucionalidad del art. 110.3 de la Ley 30/1992, y del art. 57.2.f) de la Ley reguladora de la Jurisdicción Contencioso-Administrativa, siempre que se interpretaran en el sentido que señala el párrafo $20^{\circ}$ del fundamento jurídico $7 .^{\circ}$ de la referida resolucion (...) En el presente caso, la Sala de lo Contencioso-Administrativo del Tribunal Superior de Justicia de las Islas Baleares ha optado por una interpretación puramente literal de los referidos preceptos, interpretación que determinó la inadmisión del recurso contencioso formulado por el actor. Por consiguiente, de conformidad con la doctrina contenida en la indicada STC 76/1996 ha de declararse que tal interpretación, que impide la obtención de una resolución de fondo, no resulta conforme a las exigencias derivadas del derecho a la tutela judicial efectiva. Lo cual determina la procedencia de otorgar el amparo solicitado y retrotraer las actuaciones al momento anterior al que acordó el archivo de las mismas, a fin de que la Sala proceda a dictar nueva resolución según la interpretación contenida en la citada 
RESEÑA DE SENTENCIAS DEL TRIBUNAL CONSTITUCIONAL ...

STC 76/1996 y conforme al derecho fundamental a la tutela judicial efectiva» (vid. f.j. 2).

Fallo: Otorgar el amparo solicitado y, en consecuencia:

1. Declarar que se ha lesionado al recurrente su derecho a la tutela judicial efectiva.

2. Restablecerle en su derecho y, a este fin, declarar la nulidad del Auto de 10 de enero de 1995 y de la Providencia de 20 de diciembre de 1994 dictados por la Sala de lo Contencioso-Administrativo del Tribunal Superior de Justicia de las Islas Baleares y retrotraer las actuaciones al momento anterior a dictarse los mismos a fin de que por la referida Sala se resuelva el recurso contencioso-administrativo interpuesto por el recurrente en amparo.

(Sentencia n. ${ }^{\circ}$ 65/1997, de 7 de abril. Sala Segunda. BOE de 13 de mayo de 1996. J. Gabaldón López).

6. Recurso de amparo núm. 3950/1993, formulado por la Federación Sindical de Administración Pública de Comisiones Obreras de Madrid-Región contra Sentencia de la Sala de lo Contencioso-Administrativo del TSJ de Madrid, de 17 de septiembre de 1993, recaida en recurso contra Resolución del Alcalde de Fuenlabrada, de 13 de marzo de 1989, por la que se hacía público el nombramiento de Sargentos de la Policía Municipal. A dicha sentencia imputa la entidad recurrente la lesión de los derechos a la igualdad en la aplicación de la Ley (art. $14 \mathrm{CE}$ ) y a la tutela judicial efectiva (art. 24.1 CE). El TC otorga el amparo por entender que se ha vulnerado el derecho fundamental a obtener la tutela efectiva de Jueces y Tribunales.

«En el caso de autos, la Sala requirió a la Letrada del Sindicato recurrente para "acreditar la representación que ostenta en el presente recurso". Posteriormente, declaró inadmisible el recurso por entender que no era suficiente con el poder general para pleitos aportado, sino que era necesario - según la jurisprudencia más reciente del Tribunal Supremo- que hubiera aportado el correspondiente y específico acuerdo de la Federación para recurrir, "ya que una cosa es el poder de postulación y otra bien distinta la voluntad de litigar de la persona jurídica otorgante del poder" (Fundamento de Derecho tercero). Esta misma distinción argumentada por la sentencia, debe conducirnos a la estimación de la presente demanda de amparo pues no se aprecia la señalada congruencia entre la subsanación requerida por la Sala y la causa por la que finalmente se inadmitió la demanda. Si para el órgano judicial es claro que una cosa es la postulación y otra la decisión de la persona jurídica de interponer un determi- 
nado recurso - decisión que debe ser adoptada por el órgano competente según los Estatutos y plasmarse en el correspondiente acuerdo-, no puede entenderse que el órgano judicial haya dado ocasión de subsanar este segundo requisito. La Sala se limitó a reclamar a la Procuradora que acreditara la representación que ostentaba en el recurso, lo que ésta llevó a cabo mediante la aportación de un poder general para pleitos. Sin embargo, no se requirió ni a la Federación recurrente ni a su representación procesal la subsanación de aportar el acuerdo para litigar.

Este modo de proceder se ha traducido en una lesión del derecho a la tutela judicial efectiva la Federación Sindical recurrente, a la que se ha privado de una resolución sobre el fondo por apreciar la Sala la concurrencia de un defecto de naturaleza subsanable que, sin embargo, no dio ocasión de subsanar. Se da además la circunstancia de que la necesidad o no del mencionado requisito no era una cuestión pacífica en la doctrina de la propia Sala, que en ocasiones anteriores había admitido a trámite recursos sin exigir el acuerdo de la persona jurídica litigante. Todo ello debía haber conducido a un especial cuidado del órgano judicial para facilitar la posibilidad de subsanar el defecto finalmente apreciado» (vid. f.j. 7).

Fallo: Otorgar el amparo solicitado por la Federación Sindical de Administración Pública de Comisiones Obreras de Madrid Región y, en consecuencia:

$1 .^{\circ}$ Reconocer que se ha vulnerado a la recurrente su derecho a la tutela judicial efectiva (art. 24.1 CE).

2. Restablecerle en la integridad de su derecho fundamental, para lo cual se anula la Sentencia de la Sección Sexta de la Sala de lo Contencioso-Administrativo del Tribunal Superior de Justicia de Madrid de 17 de septiembre de 1993.

3. Retrotraer las actuaciones al objeto de que se dé a la entidad recurrente la posibilidad de subsanar el defecto procesal que llevó a la inadmisión del recurso.

(Sentencia n..$^{\circ}$ 79/1997, de 21 de abril. Sala Segunda. BOE de 21 de mayo de 1997. R. de Mendizábal Allende).

7. Recurso de amparo núm. 829/1993, promovido contra la Sentencia de la Sala de lo Contencioso-Administrativo del TSJ Andalucía, con sede en Málaga, de 5 de enero de 1993, por la que se desestima el recurso, interpuesto al amparo de la Ley 62/1978, de 26 diciembre, de Protección Jurisdiccional 
RESEÑA DE SENTENCIAS DEL TRIBUNAL CONSTITUCIONAL ..

de los Derechos Fundamentales de la Persona, contra Resolución de la Alcaldia del Ayuntamiento de Fuengirola, de 26 de mayo de 1992, que considera a un policía local como responsable de dos faltas graves. El recurrente alega que la sentencia impugnada ha vulnerado el derecho fundamental a obtener la tutela judicial efectiva al haber autolimitado sus funciones en cuanto al conocimiento del fondo de las pretensiones del recurrente. El TC otorga el amparo.

«La sentencia impugnada entiende autolimitadas sus funciones en cuanto al conocimiento del fondo de las pretensiones del recurrente, por el criterio de identificar en buena medida el recurso seguido por el cauce de la Ley 62/1978, con el recurso de amparo constitucional. El punto de partida de sus razonamientos estriba en que la citada Ley instauró un proceso contencioso de naturaleza especial, sumario y urgente, que debe quedar limitado al examen de posibles lesiones de derechos fundamentales debidas a la actuación administrativa, sin que esté permitido "examinar cualquier infracción del ordenamiento jurídico, ni entrar a conocer la legalidad del acto y su adecuación al ordenamiento general". Sobre la base de esta premisa, la Sentencia impugnada afirma que debe quedar fuera de su enjuiciamiento "todo lo relativo a la adecuación a Derecho o no de la calificación jurídica de los hechos, y si éstos se reputan probados o no, ya que esto sería lo procedente en el recurso ordinario". Declara que debe circunscribir su análisis a la posible discriminación del recurrente con respecto a otros compañeros en igual situación, pero lo cierto es que tampoco entra a conocer de esta materia» (vid. f.j. 2).

«Este Tribunal no se constituye en una nueva instancia revisora acerca de los hechos (STC 7/1993), pues, por imperativo del art. 44.1, b) de la LOTC, le está vedado entrar a conocer de los mismos, cuya determinación corresponde precisamente a los órganos de la jurisdicción ordinaria cuando se solicita su tutela. Sin embargo, de la Ley 62/1978 y de su disposición supletoria, la Ley de la Jurisdicción Contencioso-Administrativa, resulta que el Tribunal competente debe actuar con plenitud de jurisdicción respecto a las circunstancias fácticas que dieran lugar a la vulneración por el acto administrativo de los derechos fundamentales que se denuncien en la demanda. Si no lo hiciera así, como ocurre en este caso, estaría dando por buena la fijación de hechos llevada a cabo por la Administración sancionadora, sin realizar la función revisora jurisdiccional que corresponde a los órganos judiciales.

De admitirse el criterio de la sentencia impugnada resultaría superflua la necesidad de agotar la vía judicial [art. 44.1, a) LOTC] para acceder al amparo constitucional. Precisamente la razón de ser de las limitaciones a que está sometido dicho recurso radica en su naturaleza subsidiaria que condiciona en diversos aspectos (hechos, preceptos aplicables y su interpretación, pruebas y su 
apreciación...) a lo que ya ha sido revisado en el procedimiento judicial previo al recurso de amparo. Las Salas de lo Contencioso-Administrativo que sustancian el procedimiento contemplado en la Ley 62/1978, como ya hemos dicho, sólo pueden relegar los aspectos de legalidad ordinaria, cuando estos aspectos no tengan relación alguna con la tutela de los derechos fundamentales comprendidos en los arts. 14 a 30 de la Constitución. Pero la Sala no sólo puede sino que debe - y ésa es su función-, conocer y pronunciarse acerca de todas las cuestiones que se planteen en la demanda, tanto de hecho como de Derecho, relacionadas con el contenido de los derechos fundamentales invocados, para, previo su enjuiciamiento y fundamentación, adoptar la resolución que estime procedente. Debe actuar, pues, con plena jurisdicción, revisando la actuación administrativa en los términos que establecen los arts. 106.1 y $117.3 \mathrm{CE}$, sin más limitación que el objeto del recurso que resuelve responda a los derechos protegidos por la vía de la Ley 62/1978» (vid. f.j. 3).

«A la luz de las anteriores consideraciones es obvio que las restricciones que se autoimpuso la Sala de lo Contencioso-Administrativo en el presente caso no encuentran fundamento en la Ley 62/1978 y han supuesto, como con razón sostiene el Ministerio Fiscal, una auténtica dejación de funciones en su tarea de controlar la actuación administrativa. Y con mayor motivo, cuando se estaba ejercitando una primera y única instancia judicial, que por eso mismo debe resolver todas las cuestiones sometidas a su enjuiciamiento. La sentencia impugnada al no hacerlo así, ha vulnerado el derecho a la tutela judicial efectiva del recurrente y hasta tanto lo haga, no puede estimarse agotada la vía judicial precedente al recurso de amparo que exigen los arts. 41.1 y 44.1 , a) de nuestra Ley Orgánica» (f.j. 4).

Fallo: Estimar el recurso de amparo interpuesto por don Juan Carlos López Carrascosa, y en su virtud:

1. Declarar que se ha vulnerado al recurrente su derecho a la tutela judicial efectiva sin indefensión.

2. Restablecerle en la integridad de su derecho, para lo cual se anula la Sentencia de la Sala de lo Contencioso-Administrativo del Tribunal Superior de Justicia de Andalucía con sede en Málaga, de 5 de enero de 1993, dictada en el recurso 1119/1992, interpuesto por la vía de la Ley 62/1978, de Protección Jurisdiccional de los Derechos Fundamentales de la Persona.

3. Retrotraer las actuaciones del mencionado recurso al momento procesal que permita a la Sala practicar la prueba y conocer y resolver todas las cuestiones planteadas en el citado recurso. 
RESEÑA DE SENTENCIAS DEL TRIBUNAL CONSTITUCIONAL ...

(Sentencia n. $95 / 1997$, de 19 de mayo. Sala Segunda. BOE de 9 de junio de 1997. F. García-Mon y González-Regueral).

8. Recurso de amparo núm. $287 / 1995$, interpuesto por la Diputación Provincial de Málaga contra la Sentencia de 6 de abril de 1990 de la Sala de lo Contencioso-Administrativo del Tribunal Superior de Justicia de Andalucía sobre declaración de incompatibilidad. Alegación de indefensión de la Administración recurrente por no haber sido debidamente emplazada en el recurso en el que se dictó la sentencia que está obligada a cumplir. El $T C$ desestima el amparo al entender que la entidad demandante tuvo conocimiento previo tanto de la existencia del procedimiento, como de la resolución que ahora impugna en amparo, si bien, a pesar de ello, no intentó ejercitar los derechos que pudieran asistirle.

«La cuestión planteada en el presente recurso de amparo consiste en determinar si, como se afirma en la demanda, la Diputación Provincial de Málaga se ha visto colocada en una situación de indefensión, lesiva del derecho reconocido en el art. 24.1 CE, por no haber sido debidamente emplazada en el recurso seguido ante la Sala de lo Contencioso-Administrativo del Tribunal Superior de Justicia de Andalucía en el que se dictó la sentencia que está obligada a cumplir. Sostiene la entidad demandante de amparo que en virtud del requerimiento de ese órgano judicial se le impone la ejecución de su pronunciamiento sin haber tenido ocasión, sin embargo, de formular alegaciones en defensa de sus intereses, lo que le habría causado una evidente y palmaria indefensión» (f.j. 1).

«Del examen de las actuaciones, cabe concluir que el aserto en que descansa la demanda, esto es, de que nunca se participó a la Diputación la existencia del proceso, no se ajusta a la realidad.

En efecto, con independencia de la cuestión de fondo acerca de si la corporación actora debió ser llamada al proceso en calidad de coadyuvante de la demandada - por tener un hipotético interés en el mantenimiento del acto recurrido-, lo cierto es que de las actuaciones se desprende que la entidad demandante tuvo conocimiento previo tanto de la existencia del procedimiento, como de la resolución que ahora impugna en amparo, si bien, a pesar de ello, no intentó ejercitar los derechos que pudieran asistirle» (vid. f.j. 5).

«En definitiva, la queja formulada por la Diputación Provincial de Málaga resulta infundada, pues con independencia del alegado desconocimiento del anuncio de interposición del recurso y del fallo de la sentencia recurrida publicados respectivamente en el "Boletín Oficial" de la provincia y de la Comuni- 
dad Autónoma, lo cierto es que a la actora le constaba indudablemente la existencia del proceso en las dos ocasiones referidas, y no puede aducir la creencia de que tal resolución no le afectaba, toda vez que en la misma se expresaba claramente la obligación de readmitir al demandante en el hospital en el que trabajaba con el abono de las correspondientes remuneraciones. $Y$, en el caso de que fuera ésta la tesis de la entidad actora, no debía haber articulado su demanda contra la sentencia aduciendo su falta de emplazamiento, sino, coherentemente, frente al requerimiento de ejecución de la Sala, o frente al auto resolutorio de un incidente de ejecución, esto es, una vez planteados ante el órgano judicial los razonamientos en virtud de los cuales consideraba que no estaba obligada a ejecutar el pronunciamiento» (f.j. 6).

Fallo: Desestimar el amparo solicitado.

(Sentencia n. ${ }^{\circ}$ 97/1997, de 19 de mayo. Sala Segunda. BOE de 9 de junio de 1997. T. S. Vives Antón).

\section{RÉGIMEN ELECTORAL}

1. Recurso de amparo núm. 2255/1994, promovido por la Junta de Andalucía, contra la Resolución de la Junta Electoral Central, de 2 de junio de 1994, parcialmente estimatoria del recurso formulado por la representación del Partido Popular contra el Acuerdo de la Junta Electoral de Andalucía por el que se rechazó la solicitud de que cesaran las campañas publicitarias llevadas a cabo por el Consejo de Gobierno de la Junta de Andalucía durante el período electoral. Alega la demandante la vulneración del derecho a la tutela judicial efectiva que se habria producido al no habérsele dado traslado del recurso que, formulado por el Partido Popular contra un Acuerdo de la Junta Electoral Andaluza, daría lugar a la mencionada Resolución parcialmente estimatoria de la Junta Electoral Central de 2 de junio de 1994; la Junta de Andalucia, pues, habria sido condenada sin que se le diera audiencia, circunstancia que, unida al dato de que contra dicha resolución no quepa «recurso administrativo o judicial alguno» (art. 21.2 LOREG), pone claramente de manifiesto - a su juicio- que se lesionó el derecho que el art. 24.1 CE consagra. El TC otorga el amparo.

«La cuestión planteada en el presente recurso es sustancialmente idéntica a la que ya suscitara el registrado bajo el núm. 2309/1994, y que sería resuelta en la STC 103/1996, otorgando el amparo. Dijimos entonces, y ahora hemos de reiterar, que, si bien sólo de modo muy excepcional "cabe aplicar ciertas garantías del art. 24.1 CE en la tramitación de procedimientos no estrictamente 
RESEÑA DE SENTENCLAS DEL TRIBUNAL CONSTTTUCIONAL ...

judiciales" (fundamento jurídico $5^{\circ}$ ), el hecho de que, en virtud del art. 21.2 LOREG, se excluya todo recurso judicial frente a las resoluciones de la Junta Electoral Central, justificaría la extensión del ámbito de cobertura del mencionado derecho fundamental a supuestos como el presente. Y es que, efectivamente, "al vetar el citado precepto de la LOREG el acceso a los Tribunales de Justicia, y ser esto una excepción a los procedimientos administrativos, también procede aplicar excepcionalmente el art. 24.1 en este caso" [fundamento jurídico $\left.4 .^{\circ}, \mathrm{c}\right)$ ]. En suma, la conculcación del derecho estriba "en que se impide de raíz la posibilidad de una tutela que la Constitución quiere que sea siempre dispensada por los Jueces y Tribunales, y que lo sea, además, en relación con todas las condiciones de juridicidad del acto o norma enjuiciados" (fundamento jurídico $7 .^{\circ}$ ).

La aplicación de esta doctrina al recurso que nos ocupa lleva derechamente a otorgar el amparo solicitado» (vid. f.j. 1).

Fallo: Estimar el presente recurso de amparo y, en consecuencia:

1. Reconocer a la recurrente su derecho a no padecer indefensión en el procedimiento especial de control electoral.

2. Anular la Resolución de la Junta Electoral Central, de 2 de junio de 1994, recaída en el expediente 290/106.

3. Retrotraer el expediente al momento en que debió darse traslado a la Junta de Andalucía del recurso interpuesto contra el Acuerdo de la Junta Electoral de Andalucía de 27 de mayo de 1994.

(Sentencia n. $.^{\circ} 46 / 1997$, de 11 de marzo. Sala Primera. BOE de 11 de abril de 1997. M. Jiménez de Parga y Cabrera).

2. Recurso de amparo núm. 2581/1984, promovido por la Junta de Andalucía contra Resolución de la Junta Electoral Central, de 24 de junio de 1994, estimatoria del recurso formulado por la representación del Partido Popular contra Acuerdo de la Junta Electoral de Andalucía por la que se desestimó la petición de que cesaran las campañas publicitarias llevadas a cabo por el Consejo de Gobierno de la Junta de Andalucía, bajo el lema "Sólo en Andalucía: tanto en tan poco tiempo», durante el periodo electoral. Aduce la demandante la vulneración del derecho a la tutela judicial efectiva que se habría producido al no habérsele dado traslado del recurso que, formulado por el Partido Popular contra un Acuerdo de la Junta Electoral Andaluza, daría lugar a la Resolución de la Junta Electoral Central, de 24 
REALA 274-275 (MAYO-DICIEMBRE, 1997)

de junio de 1994; la Junta de Andalucia, pues, habría sido condenada sin que se le diera audiencia, circunstancia que, unida al dato de que contra dicha resolución no quepa "recurso administrativo o judicial alguno» (art. 21.2 LOREG), pone claramente de manifiesto - a su juicio-que se lesionó el derecho que el art. 24.1 CE consagra. El TC otorga el amparo.

La argumentación del TC coincide sustancialmente con la recogida en la STC 46/97 (vid. supra).

Fallo: Estimar el presente recurso de amparo y, en consecuencia:

1. Reconocer a la recurrente su derecho a no padecer indefensión en el procedimiento especial de control electoral.

2. $\quad$ Anular la Resolución de la Junta Electoral Central de 24 de junio de 1994, recaída en el expediente 290/148.

3. Retrotraer el expediente al momento en que debió darse traslado a la Junta de Andalucía del recurso interpuesto contra el Acuerdo de la Junta Electoral de Andalucía, de 15 de junio de 1994.

(Sentencia n. ${ }^{\circ}$ 48/1997, de 11 de marzo. Sala Primera. BOE de 11 de abril de 1997. M. Jiménez de Parga y Cabrera).

\section{DERECHO SANCIONADOR}

1. Recurso de inconstitucionalidad núm. 1279/1988, promovido por el Gobierno Vasco contra la Ley 8/1988, de 7 de abril, sobre Infracciones y sanciones en el orden social. El TC estima parcialmente el recurso en tanto en cuanto determinados preceptos de la Ley impugnada vulneran la competencia sancionadora del País Vasco para declarar la concreta existencia de infracciones y sancionar aquellas que no guarden relación con el régimen económico de la Seguridad Social. Asimismo, el TC considera la necesidad de reelaboración de la Ley impugnada por el legislador estatal en aras del respeto y clarificación del orden constitucional de competencias y en beneficio de la seguridad jurídica en materia sancionadora.

«Hemos de efectuar el deslinde competencial en orden a la atribución de la potestad sancionadora, en cuanto a la declaración de infracciones e imposición de sanciones en materia de Seguridad Social. 
RESEÑA DE SENTENCIAS DEL TRIBUNAL CONSTITUCIONAL ...

En varias resoluciones (vgr., SSTC 87/1985, fundamentos jurídicos $1 .^{\circ}$ y $2^{\circ}$, y $227 / 1988$, fundamento jurídico 29 ) hemos afirmado que la atribución competencial de la potestad sancionadora ha de atribuirse al que tiene la competencia sobre la materia en la que se ejerce, pero, en el presente caso, la determinación genérica de la materia como ejecución en temas de Seguridad Social no resuelve el problema, desde el momento en que hay aspectos singulares de esa ejecución que se hallan atribuidos al Estado.

Para ello, según lo expuesto, hay que comenzar afirmando la potestad sancionadora del País Vasco y excluyendo, en consecuencia, la del Estado, para declarar la concreta existencia de infracciones y sancionar aquellas que no guarden relación con el régimen económico de la Seguridad Social.

Hecha esa primera atribución, es necesario proceder a una delimitación ulterior para aquellos supuestos en que la potestad punitiva recae sobre actos instrumentales respecto al nacimiento y mantenimiento de la obligación de contribuir (inscripción, afiliación, altas y bajas, etc.). En tales supuestos, como acaba de decirse, la potestad ejecutiva para la imposición de las sanciones que procedan pertenece también a la Comunidad Autónoma.

Por último, quedan aquellas infracciones que recaen directamente sobre la actividad económica de la Seguridad Social, esto es, las que definen ilícitos que se hallan inmediatamente referidos a la percepción de sus ingresos o a la realización de los gastos correspondientes. En ellas el objeto inmediato de tutela es la gestión de la caja única de la Seguridad Social que, al hallarse atribuida al Estado, determina que éste, como titular de la ejecución, ostente también la potestad de declarar infracciones e imponer sanciones, que no es sino una técnica específica de control, y que forma parte, por consiguiente, de su competencia en materia de régimen económico» (vid. f.j. 8).

«Por último, a la vista de la complejidad de las cuestiones analizadas, a la que no es ajena la sistemática de la Ley, y de la entidad del fallo que los razonamientos anteriores conducen a pronunciar, corresponde al legislador estatal reelaborar la Ley impugnada, si lo estima conveniente en aras del respeto y clarificación del orden constitucional de competencias y en beneficio de la seguridad jurídica, imprescindible en materia sancionadora» (f.j. 17).

Fallo: Estimar parcialmente el presente recurso de inconstitucionalidad contra la Ley 8/1988, de 7 de abril, y, en consecuencia:

1. Declarar que el art. 47 de la Ley 8/1988 es conforme a la Constitución, si se interpreta en la forma efectuada en el fundamento jurídico $5 .^{\circ} \mathrm{y}$, por consiguiente, reconocer la competencia del País Vasco para sancionar las infracciones 
previstas en la Sección 1. a del Capítulo Cuarto (arts. 26, 27 y 28 de la Ley), excepto la relativa al primer inciso del núm. 3 del art. 28 (obtener o disfrutar indebidamente de exenciones, bonificaciones o reducciones en las cuotas de la Seguridad Social) que corresponde al Estado en virtud de su competencia sobre el régimen económico de la Seguridad Social (art. 149.1.17).

2. Declarar que los arts. 47 y 46.4 de la Ley son contrarios al orden constitucional de competencias en cuanto desconocen las de ejecución, que ostenta la Comunidad Autónoma del País Vasco en materia de Seguridad Social y en consecuencia,

a) La potestad para sancionar las infracciones previstas en los arts. 13; 14.1 , núms. $1,2,3$ y $7 ; 16 ; 19 ; 20.1,2,3,4,6$ y $7 ; 21.1,4$ y $5 ; 22.1,2$ y 3 , $23 ; 24.1$ y $2 ; 29.1,29.2 .1$ y 30.1 y 2 , corresponde al País Vasco.

b) Corresponde al Estado la potestad de sancionar las infracciones previstas en los arts. 14.1 , núms. 4,5 y $6 ; 15 ; 17 ; 18 ; 20.5$ y $8 ; 21.2,3$ y $6 ; 23.4 ; 5$ y $6 ; 24.3$ y $4 ; 29.2$, núms. 2 , 3 y 4 y 29.3 en todos sus números y 30.3 , en virtud de su competencia sobre régimen económico de la Seguridad Social.

$3^{\circ}$ Declarar contrario al orden constitucional de competencias el art. 39 en cuanto desconoce la del País Vasco en materia de ejecución laboral.

4. Declarar contrarios al orden constitucional de competencias los núms. 1 y 2 del art. 42 de la Ley 8/1988, en cuanto desconoce las que ostenta el País Vasco, en orden a la ejecución en materia de Seguridad Social, en los términos establecidos en los fundamentos jurídicos 13 y 14 .

5. Declarar que el art. 47.1 en relación con los arts. 43 y 45 de la Ley $8 / 1988$, es contrario al orden constitucional de competencias, en cuanto desconoce las que corresponden al País Vasco en orden a la ejecución en materia laboral y de Seguridad Social.

6. Declarar que las referencias a las actuaciones de la Inspección de Trabajo y Seguridad Social, contenidas en los arts. 1.2, 11.3, 36.1, 42.1, 46.4, 47.1, 48, 49 y 52 de la Ley $8 / 1988$, en su redacción originaria, entendidas en los términos expuestos en el fundamento jurídico 16 , no vulneran el orden constitucional de competencias.

$7^{\circ}$ Desestimar el recurso en todo lo demás.

(Sentencia n. ${ }^{\circ}$ 195/1996, de 28 de noviembre. Pleno. BOE de 3 de enero de 1997. T. S. Vives Antón). 
RESEÑA DE SENTENCIAS DEL. TRIBUNAL CONSTITUCIONAL ...

2. Recurso de amparo núm. 3450/1995, promovido contra la Sentencia de 18 de julio de 1995 de la Sala de lo Contencioso-Administrativo del Tribunal Superior de Justicia de Andalucía, recaida en recurso contra el Decreto de la Alcaldía de Córdoba sancionando al ahora recurrente en amparo como autor responsable de dos faltas graves de disciplina. El demandante de amparo imputa a la resolución judicial incurrir en incongruencia omisiva al no dar respuesta a su alegación de recusación del Instructor del expediente disciplinario, vulnerando asi el derecho fundamental a obtener la tutela efectiva de Jueces y Tribunales. El TC otorga el amparo.

«De la documentación obrante en autos se desprende con claridad que la pretensión de anulación del expediente administrativo y reposición de las actuaciones al trámite de designar nuevo Instructor, que se entiende no contestada por la sentencia recurrida, fue efectivamente planteada tanto a lo largo de todo el procedimiento administrativo como ante el Tribunal contencioso, conjuntamente con la pretensión subsidiaria de fondo (...) En consecuencia, debemos concluir que la pretensión supuestamente no resuelta por el órgano judicial fue efectivamente suscitada, desde un punto de vista procesal, oportunamente por el ahora actor. Pero, es más: se trata de una cuestión con decisiva relevancia para la solución final del litigio, pues, de prosperar, podría haber impedido una decisión de fondo sobre la cuestión litigiosa, esto es, sobre la procedencia de las sanciones impuestas.

Por otra parte, y en relación con los pronunciamientos de la sentencia del Tribunal Superior de Justicia, procede también declarar que no se da en los mismos contestación expresa a aquella pretensión. Asimismo, tampoco puede deducirse de otros razonamientos de la sentencia una respuesta tácita a la cuestión planteada, pues éstos centraron su atención de manera exclusiva en las pretensiones de fondo suscitadas por las partes.

Cabría plantearse si el hecho de que la Sala haya entrado a decidir directamente sobre el fondo del asunto no puede interpretarse, precisamente, como una desestimación implícita de la nulidad solicitada por el actor. $\mathrm{O}$ dicho de otro modo: si al órgano judicial no le pudo pasar desapercibida tal cuestión y, sin embargo, se limitó a decidir sobre el fondo, pudiendo así concluir que no la consideró relevante. Sin embargo, como también pusimos de manifiesto en la STC $91 / 1995$, tal planteamiento resulta poco respetuoso, en casos como el presente, no sólo con lo dispuesto en el art. 120.3 de la CE sino, también, con el art. 24.1 CE que, como antes se ha indicado, implica la obligación de los órganos judiciales de pronunciarse motivadamente sobre todas las pretensiones; obligación, que si bien no exige una exhaustiva descripción del proceso intelectual que lleva al órgano judicial a adoptar una solución determinada, ni le impone un concreto alcance o intensidad en el razonamiento empleado 
(SSTC 100/1987 y 109/1992), sí supone al mismo tiempo "una garantía esencial del justiciable mediante la cual, sin perjuicio de la libertad del Juez en la interpretación de las normas, se pueda comprobar que la solución dada al caso es consecuencia de una exégesis racional del ordenamiento y no el fruto de la arbitrariedad" (STC 116/1986). Cuando esta respuesta razonada no se produce, ni es posible deducirla razonablemente de las circunstancias que rodean al caso concreto o de otras afirmaciones de la sentencia, no se respetan las garantías del art. 24.1 CE (STC 91/1995), como ahora es el caso.

En consecuencia, por todo lo expuesto, debemos otorgar el amparo en relación con esta concreta alegación y anular, como se pide, la sentencia impugnada al objeto de que la Sala de lo Contencioso-Administrativo del Tribunal Superior de Justicia de Andalucía proceda a dictar nueva resolución en la que resuelva expresa y motivadamente sobre la pretensión de anulación del expediente disciplinario por la causa aducida» (vid. f.j. 3).

Fallo: Estimar parcialmente el recurso de amparo interpuesto por don Antonio Delgado García y, en consecuencia:

$1 .^{\circ}$ Reconocer al recurrente su derecho a la tutela judicial efectiva.

2. Anular la Sentencia dictada por la Sala de lo Contencioso-Administrativo en Sevilla del Tribunal Superior de Justicia de Andalucía, de 18 de julio de 1995, recaída en recurso contra el Decreto de la Alcaldía de Córdoba, de 27 de abril de 1994, sobre sanción.

3. Retrotraer las actuaciones al momento inmediatamente anterior al de dictarse la sentencia anulada, a fin de que dicho Tribunal dicte otra congruente con la totalidad de las pretensiones deducidas por las partes.

(Sentencia n..$^{\circ}$ 94/1997, de 8 de mayo. Sala Primera. BOE de 9 de junio de 1997. V. Gimeno Sendra).

\section{DERECHO URBANÍSTICO}

1. Cuestión de inconstitucionalidad núm. 278/1991, promovida por la Sección Quinta de la Sala Tercera del Tribunal Supremo, por supuesta inconstitucionalidad de las Leyes del Parlamento de las Islas Baleares 1/1984, de 14 de marzo, de Ordenación y Protección de Áreas Naturales de Interés Especial, y 3/1984, de 31 de mayo, de declaración de "Es Trenc-Salobrar de Campos», como Área Natural de Especial Interés, por poder vulnerar las competencias estatales sobre protección del medio ambiente, además 
RESEÑA DE SENTENCIAS DEL TRIBUNAL CONSTTTUCIONAL ...

de los arts. 14 y 33 de la Constitución. El TC desestima la cuestión al entender que las leyes impugnadas establecen disposiciones normativas urbanisticas.

«Cabe concluir que las Leyes $1 / 1984$ y $3 / 1984$, de las Islas Baleares, establecen disposiciones normativas típicamente urbanísticas y directamente orientadas a la planificación territorial y a la delimitación de los usos del suelo, por lo que han de encuadrarse en el título competencial relativo a la "Ordenación del territorio y urbanismo".

Tanto la Constitución (art. 148.13. ${ }^{\text {a) }}$ como el Estatuto de Autonomía de las Islas Baleares (art. 10.3) reconocen a esta Comunidad Autónoma competencia exclusiva sobre la indicada materia. Por tanto, desde esta óptica, las leyes cuestionadas no ofrecen reparo alguno de constitucionalidad, máxime cuando en atención a sus específicos contenidos, tampoco puede apreciarse la duda de la Sala sobre la supuesta contradicción por alguno de sus preceptos de lo dispuesto en la legislación básica del Estado en materia de medio ambiente, contenida, al tiempo de plantearse la presente cuestión de inconstitucionalidad, en la Ley 4/1989 (LCEN).

Los términos abstractos en los que se formula esta duda en el auto de planteamiento, sin la más mínima concreción de la contradicción que simplemente se apunta, impiden a este Tribunal hacer mayores precisiones. Porque si bien es cierto que, como ha quedado razonado en los anteriores fundamentos, el título competencial desde el que actúa la Comunidad Autónoma ha de respetar y no contradecir la legislación básica del Estado sobre protección del medio ambiente, para examinar esa cuestión han de facilitarse los datos que originan la duda sin que pueda este Tribunal suplir la indeterminación en que incide la Sala» (vid. f.j. 6).

Fallo: Desestimar la cuєstión de inconstitucionalidad.

(Sentencia n. $.^{\circ} 28 / 1997$, de 13 de febrero. Pleno. BOE de 14 de marzo de 1997. F. García-Mon y González Regueral).

2. Recursos de inconstitucionalidad acumulados núms. 2477/1990, 2479/1990, 2481/1990, 2486/1990, 2487/1990, 2488/1990, promovidos, respectivamente, por el Parlamento de Navarra, el Consejo de Gobierno de la Diputación Regional de Cantabria, el Consejo Ejecutivo de la Generalidad de Cataluña, la Diputación General de Aragón, la Junta de Castilla y León y el Gobierno de Canarias, en relación con la Ley 8/1990, de 25 de julio, sobre Reforma del Régimen Urbanistico y Valoraciones del Suelo, y re- 
cursos de inconstitucionalidad, acumulados a los anteriores, núms. 2337/1992, 2341/1992, 2342/1992, interpuestos, respectivamente, por el Consejo de Gobierno de la Comunidad Autónoma de las Islas Baleares, la Diputación General de Aragón y el Consejo Ejecutivo de la Generalidad de Cataluña frente al Texto Refundido de la Ley sobre el Régimen del Suelo y Ordenación Urbana, aprobado por Real Decreto Legislativo 1/1992, de 26 de junio. El TC estimó parcialmente los recursos y declaró la inconstitucionalidad y nulidad de diversos preceptos calificados de "carácter básico» o de "aplicación plena» 0 dotados de eficacia supletoria en la disposición final única del Texto Refundido citado, asi como la nulidad de la disposición derogatoria única de ese Texto Refundido, limitándose la derogación a la Ley 8/1990, de 25 de julio.

«El orden constitucional de distribución de competencias ha diseccionado ciertamente la concepción amplia del urbanismo que descansaba en la legislación anterior a la Constitución de 1978, pues no es posible desconocer, como se ha dicho, que junto a la atribución de la competencia urbanística a las Comunidades Autónonas, el art. 149.1 CE reconoce al Estado la competencia, también exclusiva, sobre las condiciones básicas de ejercicio de los derechos constitucionales o la legislación sobre expropiación forzosa, o el sistema de responsabilidad o el procedimiento administrativo común, por citar algunos de los instrumentos de los que el urbanismo, con esa u otra nomenclatura, suele hacer uso.

Pues bien, expuesto lo anterior, ha de afirmarse que la competencia exclusiva sobre urbañismo ha de integrarse sistemáticamente en aquellas otras estatales que, si bien en modo alguno podrían legitimar una regulación general del entero régimen jurídico del suelo, pueden propiciar, sin embargo, que se afecte puntualmente a la materia urbanística (establecimiento de las condiciones básicas que garanticen la igualdad en el ejercicio del derecho de propiedad urbana, determinados aspectos de la expropiación forzosa o de la responsabilidad administrativa). Pero ha de añadirse, a renglón seguido, que no debe perderse de vista que en el reparto competencial efectuado por la CE es a las Comunidades Autónomas a las que se ha atribuido la competencia exclusiva sobre el urbanismo, y por ende es a tales Entes públicos a los que compete emanar normas que afecten a la ordenación urbanística» (vid. f.j. 6).

«Así las cosas, dado que a partir de los arts. 148 y $149 \mathrm{CE}$, todos los Estatutos de Autonomía atribuyen a las Comunidades Autónomas la competencia exclusiva sobre la materia de urbanismo, es evidente que el Estado no puede dictar normas supletorias al carecer de un título competencial específico que así lo legitime, sin que por otra parte el hecho de ostentar otros títulos compe- 
RESEÑA DE SENTENCIAS DEL TRIBUNAL CONSTITUCIONAL ..

tenciales susceptibles de incidir sobre la materia pueda justificar la invocación de la cláusula de supletoriedad del art. 149.3 in fine CE.

La calificación como normas supletorias, pues, en coherencia con cuanto se ha dicho, es contraria al art. 149.3 CE in fine y al orden constitucional de competencias. En consecuencia, han de ser declarados inconstitucionales tanto el apartado $3 .^{\circ}$ de la Disposición final única como los preceptos así calificados, esto es, todos aquellos que, de conformidad con lo que establece la indicada Disposición, no tienen carácter de norma básica ni de aplicación plena.

Es de apreciar, en fin, que la imposibilidad de dictar normas supletorias con tal exclusivo propósito allí donde el Estado carece de competencias sobre la materia, como en el caso del urbanismo, trae también como consecuencia que la refundición de textos legales no sea la técnica legislativa más adecuada en manos del legislador estatal, puesto que, a menos que tal refundición se circunscriba a aquellos textos legales o normas sobre las que el Estado sí ostente algún título, incurriría en vicio de incompetencia. En el caso del TRLS, además, se ha perseguido llevar a cabo la refundición de textos legales anteriores a la Constitución -con una pretensión evidentemente codificadora merced a un entendimiento de la supletoriedad como título atributivo-, siendo así que tras su promulgación, la materia ha sido atribuida sustancialmente a las Comunidades Autónomas. Como es obvio, la delegación legislativa debe ser igualmente respetuosa con el orden constitucional de competencias.

d) La declaración de inconstitucionalidad del apartado tercero de la Disposición final única, así como de las propias disposiciones por ella concernidas, en aplicación de nuestra doctrina sobre la cláusula de supletoriedad, debe conducir a la declaración de la inconstitucionalidad por consecuencia (art. 39.1 LOTC) del apartado primero de la Disposición derogatoria única.

$\mathrm{Si}$, como hemos señalado, la cláusula de supletoriedad no es una fuente atributiva, en positivo, de competencias estatales, ni aun con carácter supletorio, tampoco puede serlo en negativo; es decir, tampoco puede ser un título que le permita al Estado derogar el que era su propio Derecho, en este caso sobre urbanismo, pero que ya ha dejado de serlo o, más exactamente, que ya no se encuentra a su disposición, ya sea para alterarlo (aun con eficacia supletoria) o para derogarlo. De otro modo, si el legislador estatal suprimiese, mediante su derogación, el Derecho sobre una materia cuya competencia ya no es suya, sino de las Comunidades Autónomas, vendría a quebrantar una de las finalidades básicas de la cláusula de supletoriedad, cual es la de que, con la constitución de los órganos de poder de las Comunidades Autónomas, y su correspondiente asunción de competencias normativas, no se origine un vacío parcial del orde- 
namiento, permitiendo y prescribiendo, con este propósito, la aplicación supletoria, potencialmente indefinida, del ordenamiento estatal.

En el caso que nos ocupa, como se ha declarado, el TRLS ha alterado el sentido propio de la cláusula de supletoriedad, habiendo venido a efectuarlo mediante dos operaciones, que sin embargo van inescindiblemente unidas: De una parte, alterando la legislación urbanística previa a la constitución de los órganos de poder de las Comunidades Autónomas, aun cuando fuera con eficacia supletoria, sobre la que ya carecía de competencia; de otra parte, derogando, no sólo de forma tácita sino también de forma expresa (Disposición derogatoria única, apartado primero, TRLS), dicha legislación urbanística previa. La consecuencia de todo ello, a nuestros efectos, no es sino la de que, una vez declarada la ilegitimidad de la legislación supletoria sobre urbanismo llevada a cabo por el Estado con apoyo en una comprensión errada de la supletoriedad, debamos, al mismo tiempo, declarar nula y sin efecto la simultánea derogación expresa de la legislación urbanística previa a la constitución de los órganos de poder de todas las Comunidades Autónomas llevada a cabo por el legislador estatal. De no hacerlo así, es decir, si nos limitásemos a la declaración de nulidad del citado apartado tercero de la Disposición final única, vendríamos a ocasionar, por obra de nuestra propia Sentencia, un resultado contrario al señalado sentido de la cláusula de supletoriedad establecida en el inciso tercero del art. 149.3. CE.

De acuerdo, por tanto, con lo anterior, procede declarar la inconstitucionalidad por consecuencia del apartado primero de la Disposición derogatoria única, con la sola excepción del inciso final "y la Ley 8/1990, de 25 de julio, sobre Reforma del Régimen Urbanístico y Valoraciones del Suelo", en la medida en que dichas disposiciones no se extiendan a materias sobre las que el Estado no ostente competencias, y sin perjuicio del efecto derogatorio tácito que puedan desplegar las disposiciones del TRLS dictadas por el Estado en el marco de sus competencias» (vid. f.j. 12).

Fallo: Estimar parcialmente los recursos contra el Texto Refundido de la Ley sobre el Régimen del Suelo y Ordenación Urbana aprobado por Real Decreto Legislativo 1/1992, de 26 de junio, y en su virtud:

1. Declarar que son inconstitucionales y nulos los siguientes preceptos calificados de «carácter básico» o de «aplicación plena» en los apartados primero y segundo de la Disposición final única:

$-11.4,-20.1$ b) en su inciso «a los Ayuntamientos». -27.1, 2 y 4, -29.1, -30.1, -30.3, en su segundo inciso, «El Ayuntamiento decidirá sobre la expropiación o sujeción al régimen de venta forzosa de los correspondientes terre- 
RESEÑA DE SENTENCIAS DEL TRIBUNAL CONSTITUCIONAL ...

nos, cuyo valor se determinará, en todo caso, con arreglo a la señalada reducción del aprovechamiento urbanístico». -31.1 y $2,-32,-34,-35.1,-36.2$, -38.2 y $3,-39$, en su inciso «mediante solicitud de la correspondiente licencia en el plazo que establezca la legislación urbanística aplicable o, en su defecto, en el de dos meses a contar desde el oportuno requerimiento, si ya se hubiese adquirido el derecho al aprovechamiento urbanístico. Si faltase sólo para la adquisición del mencionado derecho la realización de la urbanización, la legalización exigirá también el cumplimiento de dicho deber». -40.3 , -42.1 y $2,-42.3$, en su segundo inciso, «con la particularidad de que el aprovechamiento susceptible de apropiación se reducirá en un $50 \%$, cuando no se hubiera adquirido ese derecho en el momento de la notificación del incumplimiento». 59.1 y $2,-60,-61.1,-62,-65,-66,-67,-72.1,-78.2,-94.1$ y 2 , $-95,-96.1$ y $3,-97,-98,-99.1$ y $2,-104.1,-107,-109.1,-112,-118.1,-124.2$, $-126.1,-135.2,-141,-143,-144.1,-149.3,-151.1$ y $3,-154.2,-166.1$ a), c) y e), $-167,-174.2,-176,-199.1$ b) y 2 b), $-202.1,2,3$ y $4,-205,2$ y $3 .-206.1$ a excepción de la letra f), y 206.2, $-207,-220.1,-221,-227.1$, en su primer párrafo: «En los supuestos de incumplimiento de deberes urbanísticos contemplados en la presente Ley, cuando la Administración actuante no opte por la expropiación, acordará la aplicación del régimen de venta forzosa del terreno». -228.3, en su inciso «según el aprovechamiento tipo vigente al tiempo de la tasación». $-248,-249,-254.1,-277,-278.1$ y $4,-282.2,-284.3$, $-285,-286,-299$, inciso final: «con arreglo a esta Ley». -Disposición adicional primera. -Disposición adicional tercera. -Disposición adicional cuarta, regla $2{ }^{\mathrm{a}}$. - Disposición transitoria primera, apartados 2 y 4. -Disposición transitoria cuarta. - Disposición transitoria quinta, apartado 2 , último inciso: «En todo caso, como valor mínimo del suelo se entenderá el resultante de la aplicación del $85 \%$ del aprovechamiento tipo vigente al tiempo de la valoración». -Disposición transitoria sexta, apartados 1 y 4. -Disposición transitoria octava.

2. Declarar que son inconstitucionales y nulos el apartado $30^{\circ}$ de la Disposición final única y, consiguientemente, los siguientes preceptos aprobados por el Estado con eficacia supletoria:

Art. 1; art. 2; art. 3, apartado 2, letras: a, b, d, e, f, g, h, i, j, k y apartados 3 a 6; art. 4, apartados 2 y 3; art. 9, apartado 2; art. 10; art. 11, apartados 1 a 3; art. 12; art. 13; art. 14; art. 16, apartado 3; art. 18; art. 24, apartado 2; art. 27. apartado 3; art. 28, apartados 2 a 4; art. 29, apartado 2; art. 30, apartados 2,4 y 5 ; art. 31 , apartado 3; art. 33, apartado 2; art. 42, apartados 4 y 5; art. 43, apartado 2; art. 44; art. 45, apartado 5; art. 59, apartado 3; art. 65, apartados 2 a 6; art. 68; art. 69; art. 70; art. 71; art. 72, apartados 2 a 5; art. 73; art. 74; art. 75; art. 76; art. 77; art. 78, apartados 1 y 3; art. 79; art. 80; art. 81; art. 82; art. 83; art. 84; art. 85; art. 86; art. 87; art. 88; art. 89; art. 90; art. 91; art. 92; 
art. 93; art. 94; art. 96, apartado 2; art. 99, apartado 3; art. 101; art. 102; art. 103; art. 104, apartado 2; art. 105; art. 106; art. 108; art. 109, apartados 2 a 5; art. 110; art. 111; art. 113, apartado 1; art. 114; art. 115; art. 116; art. 117; art. 118, apartados 2 a 4; art. 119; art. 120; art. 121; art. 122; art. 123; art. 125; art. 126, apartados 2 a 6; art. 127; art. 128; art. 129; art. 130; art. 131; art. 134, apartado 2; art. 136, apartado 1; art. 137, apartados 1 a 4; art. 138, letra a; art. 139; art. 142; art. 144, apartados 2 y 3; art. 145; art. 146; art. 147; art. 148; art. 149, apartados 1,2 y 4; art. 151, apartados 2 y 4; art. 152; art. 153; art. 155; art. 156; art. 157; art. 158; art. 159, apartados 1 a 3; art. 160, apartados 1 y 2 ; art. 161; art. 162; art. 163; art. 164; art. 165; art. 166, apartado 1 , letras, b, d, f, g, y apartados 2 y 3; art. 170, apartado 2; art. 171; art. 172; art. 174, apartado 1; art. 175; art. 177; art. 178; art. 179; art. 180, apartado 1; art. 181; art. 182; art. 184, apartado 1; art. 185; art. 186; art. 187; art. 188; art. 189; art. 190; art. 191; art. 192; art. 193; art. 194; art. 195; art. 196; art. 197; art. 198; art. 199, apartado 1, letra a, apartado 2, letras a y b; art. 200; art. 201; art. 202, apartado 5; art. 208; art. 209; art. 211, apartados 1 y 2; art. 212; art. 227, apartado 2; art. 228, apartados 1 y 2 ; art. 229; art. 230; art. 231; art. 233; art. 234; art. 236; art. 242, apartados 2 a 5 y 7; art. 243, apartado 3; art. 244, apartados 1 y 5 ; art. 245, apartado 2; art. 246, apartados 1 y 3; art. 247; art. 250; art. 251; art. 252; art. 253, apartados 1 y 2; art. 254, apartado 3; art. 255, apartado 1; art. 256; art. 257; art. 258, apartado 1; art. 259, apartados 1, 2 y 4; art. 260; art. 261; art. 262; art. 263; art. 264; art. 265; art. 266; art. 267; art. 268; art. 269; art. 270; art. 271; art. 272; art. 273; art. 275; art. 278, apartados 2 y 3; art. 279; art. 280, apartado 2; art. 281; art. 282, apartado 1; art. 283; art. 284, apartados 1 y 2; art. 287, apartado 1; art. 288, apartado 1; art. 290; art. 291; art. 292; art. 293; art. 294; art. 295; art. 297; art. 298; Disposición adicional segunda; Disposición transitoria segunda; Disposición transitoria tercera; Disposición transitoria sexta, apartados 2, 3 y 5; Disposición transitoria séptima.

3. Declarar la inconstitucionalidad y nulidad del apartado primero de la Disposición derogatoria única en el inciso «las siguientes normas de rango legal: El Real Decreto 1346/1976, de 9 de abril, por el que se aprueba el texto refundido de la Ley sobre Régimen del Suelo y Ordenación Urbana; el Real Decreto-ley $3 / 1980$, de 14 de marzo, sobre creación de suelo y agilización de la gestión urbanística; el Real Decreto-Ley 16/1981, de 16 de octubre, de adaptación de Planes Generales de Ordenación Urbana, y», viniendo, por tanto, a decir: «Queda derogada la Ley 8/1990, de 25 de julio, sobre Reforma del Régimen Urbanístico y Valoraciones del Suelo», en los términos precisados en el fundamento jurídico $12 \mathrm{~d}$ ).

4. Desestimar los recursos en todo lo demás. 
RESEÑA DE SENTENCIAS DEL TRIBUNAL CONSTITUCIONAL ...

(Sentencia n. ${ }^{\circ} 61 / 1997$, de 20 de marzo. Pleno. BOE de 25 de abril de 1997. E. Ruiz Vadillo. Voto particular formulado por M. Jiménez de Parga y Cabrera).

\section{DERECHO PÚBLICO DE LA ECONOMÍA}

\section{A) Agricultura}

1. Conflicto positivo de competencia núm. 1693/1989, promovido por el Gobierno del País Vasco, frente a la Orden del Ministerio de Agricultura, Pesca y Alimentación, de 13 de abril de 1989, que modifica parcialmente la de 5 de diciembre de 1988, por la que se establecen las normas de aplicación del régimen de ayudas destinado a fomentar la retirada de tierras de la producción. En concreto, la Comunidad Autónoma del País Vasco circunscribe la vindicatio potestatis a tres extremos de la referida Orden ministerial de 13 de abril de 1989: la Administración a la que corresponde el pago de las ayudas (art. 11, núm. 5); la adopción de los modelos en los que han de consignarse las solicitudes de ayuda y los pertinentes actos de comunicación de dichas solicitudes y de las resoluciones de otorgamiento (anexos III y IV de la Orden ministerial, en relación con los arts. 10.1 y 11.1 y 2); y, por último, la fijación del listado de explotaciones sobre las que ha de versar el control anual previsto en el art. 15 del Real Decreto 1435/1988, de 25 de noviembre (art. 11.7 de la Orden ministerial). El TC estima parcialmente el conflicto y entiende que corresponde a la Comunidad Autónoma del País Vasco el pago de las ayudas y la adopción de los modelos de solicitud, y al Estado la fijación del listado de explotaciones sobre las que ha de versar el control anual.

«Cabe observar que el art. 10.1 de la Orden ministerial aquí cuestionada, al modificar el texto de la precedente, atribuye a las Comunidades Autónomas tanto la recepción de las solicitudes de ayuda como, en virtud del art. 11.1, la competencia para dictar "la correspondiente resolución de concesión". Estando investidas, pues, de la potestad de incoar, instruir y resolver los expedientes administrativos. Por lo que en el presente caso ha de estarse a lo expuesto en la citada STC 79/1992, fundamento jurídico $5 .^{\circ}$, donde se ha declarado que el acto de pago es instrumental, pues "lo sustantivo es la decisión que confiere o deniega el derecho a percibir las ayudas"; y por constituir, además, un acto de ejecución, "debe corresponder en principio a las Comunidades Autónomas con competencia en la materia", en este caso la agricultura, sin que pueda menoscabarse indebidamente tal competencia mediante la sustracción de una actuación puramente ejecutoria de una decisión adoptada por ellas (...) Por lo que ha de concluirse que la competencia para el pago de las ayudas aquí consideradas corresponde a la Comunidad Autónoma del País Vasco» (vid. f.j. 3). 
«La adopción de un único modelo oficial, por tratarse de un aspecto meramente procedimental, no puede considerarse que tenga un carácter básico, como se ha dicho respecto a un supuesto similar en la STC 79/1992, fundamento jurídico $6 .^{\circ} \mathrm{N}$ ) y, asimismo, que la gestión administrativa de las ayudas, en este caso atribuida a las Comunidades Autónomas, comprende, entre otros extremos, la recepción de las solicitudes, la verificación de sus datos y su tramitación, como antes se ha dicho. Competencia de la que sin dificultad se deriva la facultad de la Administración ante la que se tramitan las ayudas para decidir el empleo de los modelos o formularios más apropiados que han de utilizar los solicitantes así como los que han de utilizarse para resolver sobre su otorgamiento» (vid. f.j. 4).

«Resulta legítimo que el Estado establezca medidas de coordinación fijando anualmente el listado de explotaciones a controlar. Pues si bien existen otras posibilidades para la realización de esta función, como ha alegado la Comunidad Autónoma que plantea el conflicto, no nos corresponde decidir cuál sea la fórmula precisa preferible (STC 79/1992, fundamento jurídico $4 .^{\circ}$ ). Y la establecida en el precepto impugnado, que se basa en la adecuada información procedente de la Comunidad Autónoma, en nada menoscaba sus competencias en la materia, siendo su finalidad la de garantizar la adecuada distribución geográfica de la muestra y un tratamiento homogéneo de los datos resultantes de esa verificación en todo el territorio nacional (...) Ha de llegarse, pues, a la conclusión de que corresponde al Estado fijar el listado de explotaciones que han de ser controladas mediante la muestra prevista en el art. 15.1 del Real Decreto $1435 / 1988$ de 25 de noviembre, al que se remite el art. 11.7 de la Orden Ministerial aquí controvertida» (vid. f.j. 5).

Fallo: Estimar parcialmente el conflicto positivo de competencia planteado por el Gobierno del País Vasco y, en consecuencia:

1. Declarar que las competencias controvertidas en relación con el apartado 5 del art. 11 , así como respecto a los modelos oficiales a los que se refieren los arts. 10.1 y 11.1 y 2 de la Orden ministerial de 5 de diciembre de 1988, en la redacción dada por la de 13 de abril de 1989, y que figuran como anexos III y IV de esta última, corresponden a la Comunidad Autónoma del País Vasco.

2. Declarar que la competencia controvertida en relación con el art. 11.7 de la Orden Ministerial de 5 de diciembre de 1988, en la redacción dada por la de 13 de abril de 1989, corresponde al Estado.

(Sentencia n. 70/1997, de 10 de abril. Pleno. BOE de 13 de mayo de 1997. J. D. González Campos). 
RESEÑA DE SENTENCIAS DEL TRIBUNAL CONSTTTUCIONAL ...

\section{B) Comercio}

1. Conflicto de competencia núm. 1015/1988, promovido por el Gobierno de la Nación contra los artículos 11.5 y 14.1.1 del Decreto 411/1987, de 22 de diciembre, del Consejo Ejecutivo de la Generalidad de Cataluña, sobre reestructuración del Departamento de Comercio, Turismo y Consumo en la redacción dada por los arts. 5. .5 y 8...1 del Decreto 155/1988. El TC desestima el conflicto puesto que éste no tiene como función la de prevenir posibles interpretaciones contrarias a la Constitución por parte de quienes están llamados a aplicar las disposiciones delimitadoras de competencias (que es lo que podría ocurrir en este caso), sino la de eliminar transgresiones concretas y efectivas de los respectivos ámbitos competenciales.

«Si bien el presente conflicto positivo de competencia fue formulado frente a los arts. 11.5 y 14.1 del Decreto $411 / 1987$, de 22 de diciembre, de reestructuración del Departamento de Comercio, Consumo y Turismo de la Generalidad de Cataluña, el Pleno de este Tribunal debió declarar, mediante Auto de 22 de noviembre de 1988 , literalmente, que "el conflicto se plantea frente al texto resultante de la última actividad normativa de la Generalidad, es decir, frente a los arts. 11.5 y 14.1 .1 del Decreto $411 / 1987$, en la redacción que les dio el Acuerdo de 28 de abril de 1988, y que en la actualidad se recoge en los arts. 5.5 y 8.1.1 del Decreto catalán 155/1988”. Estos últimos fueron efectivamente los preceptos cuya suspensión se mantuvo en el citado auto y sobre cuya adecuación al bloque de la constitucionalidad ahora hemos de pronunciarnos (...) Lo esencial a retener es que el conflicto se plantea ante nosotros frente a unos preceptos cuyo contenido el Consejo Ejecutivo resuelve modificar en el Acuerdo por el que se responde al requerimiento de incompetencia facultativo formulado previamente por el Gobierno ... Sólo con el Decreto 155/1988, de 11 de julio, nacen, finalmente, a la vida jurídica los anunciados nuevos contenidos, con ocasión de la reorganización del Departamento de Industria y Energía de la Generalidad, al que pasa a incorporarse la Dirección General de Promoción Comercial, ahora como arts. 5.5 y 8.1.1 del citado Decreto. Son, por tanto, estos preceptos los únicos que interesan a los efectos del presente conflicto» (vid. f.j. 1).

«Los citados preceptos son impugnados por vulnerar las competencias exclusivas que la Constitución reserva al Estado en su art. 149.1.3. ${ }^{\mathrm{a}}$ y 10. ${ }^{\mathrm{a}}$, es decir, las materias de relaciones internacionales y comercio exterior. El primero de los preceptos impugnados atribuye a la Dirección General de Promoción Comercial la programación y realización de acciones "a fin de incrementar las posibilidades de introducción de las producciones catalanas en los distintos mercados, sin perjuicio de las competencias que constitucionalmente corres- 
ponden al Estado"; el segundo encomienda al Servicio de Promoción Exterior de dicha Dirección General, de conformidad a su vez con las competencias del Departamento, "organizar jornadas, seminarios y todo tipo de actos encaminados a facilitar la introducción de las producciones catalanas en los distintos mercados".

La denunciada invasión competencial sólo puede adquirir sentido teniendo en cuenta el contenido de los preceptos frente a los que inicialmente el Gobierno de la Nación requirió a la Generalidad de incompetencia. En los mismos se decía "los mercados internacionales" allí donde luego los preceptos rezan "los distintos mercados". El Gobierno de la Nación entiende que el sentido del precepto "sigue siendo el mismo"; una sincera aceptación del requerimiento habría llevado a hablar de "mercados interiores"; la dicción "distintos mercados" no puede interpretarse sino entendiendo comprendidos dentro de los mismos a los internacionales.

Frente a ello, el Consejo Ejecutivo de la Generalidad de Cataluña responde que pretender que la expresión "distintos mercados" comporta un exceso de competencia es hacer una interpretación apriorística y parcial, prejuzgando que la Generalidad desarrollará una actividad en determinados mercados donde pudiera carecer de competencia para ejercerla» (f.j. 2).

«El conflicto positivo de competencia debe ser desestimado. Es, en efecto, doctrina de este Tribunal que "el conflicto de competencias no tiene como función la de prevenir posibles interpretaciones contrarias a la Constitución por parte de quienes están llamados a aplicar las disposiciones delimitadoras de competencias" (STC 13/1988, fundamento jurídico $4 .^{\circ}$ ), sino la de eliminar transgresiones concretas y efectivas de los respectivos ámbitos competenciales; no es la suya, en consecuencia, una función preventiva, sino reparadora.

En el presente caso, es patente que las normas finalmente objeto de conflicto, a diferencia de lo que sucedía en su redacción originaria, están desprovistas de toda referencia a los "mercados internacionales". Los preceptos objeto del conflicto, en virtud de la sustitución, primero sólo acordada y finalmente hecha efectiva, como consecuencia del oportuno requerimiento, se refieren a "los distintos mercados". Dentro de tal expresión, como es obvio, no cabe excluir que puedan comprenderse también los mercados "internacionales", pero desde luego no de manera necesaria. La expresión es lo suficientemente genérica como para impedir, por nuestra parte, cualquier otra declaración que no viniera a resultar puramente cautelar o preventiva. El Gobierno de la Nación está en su pleno derecho al temer una actuación futura en el sentido indicado por parte del Departamento en cuestión de la Generalidad catalana, pero la materialización de tal conducta no será, en modo alguno, consecuencia necesaria de los preceptos 
RESEÑA DE SENTENCIAS DEL TRIBUNAL CONSTITUCIONAL ...

impugnados, a cuya dicción no puede reprocharse invasión de las competencias exclusivas estatales invocadas en el presente conflicto. A ello viene a sumarse el que, en aplicación de la doctrina antes señalada, este Tribunal no hace pronunciamientos preventivos; sólo en el supuesto de una aplicación de aquellas normas en la que se dé lugar a una actuación exterior a nuestras fronteras por parte de aquellos organismos podrá tenerse por ejercida una competencia que, considerada propia por el Gobierno, será preciso adscribir por este Tribunal a una u otra de las entidades que, en su caso, se disputen su titularidad. En tanto tal cosa no suceda, el presente conflicto, en los términos actualmente planteados, debe ser desestimado» (f.j. 3).

Fallo: Desestimar el presente conflicto positivo de competencia.

(Sentencia n..$^{\circ}$ 15/1997. de 30 de enero. Pleno. BOE de 26 de febrero de 1997. P. Cruz Villalón).

\section{C) Energía. Petróleo}

1. Recurso de inconstitucionalidad núm. 847/1993, promovido por el Consejo Ejecutivo de la Generalidad de Cataluña contra la Disposición Final Tercera de la Ley 34/1992, de 22 de diciembre, de Ordenación del Sector Petrolero. El TC estima parcialmente el recurso y declara que la Disposición final tercera de la mencionada Ley no es conforme con el orden constitucional de competencias en tanto que atribuye carácter básico a determinados preceptos.

«A fin de delimitar adecuadamente el objeto del presente recurso conviene señalar, en primer lugar, que si bien la impugnación del Consejo Ejecutivo de la Generalidad de Cataluña se dirige contra la Disposición final tercera de la Ley 34/1992, de 22 de diciembre, de ordenación del sector petrolero, cuya inconstitucionalidad y consiguiente nulidad se solicita que declaremos, en realidad la impugnación se concreta al inciso primero de dicha Disposición final, que atribuye carácter básico no sólo a los preceptos contenidos en la Ley $34 / 1992$, sino también a las disposiciones reglamentarias expresamente habilitadas en la misma y a las actuaciones relacionadas en los núms. 1 y 2 del art. 10. Con la particularidad, en segundo término, de haberse calificado como impugnados en la demanda varios preceptos de dicha Ley, a saber, los arts. 8.2 y 3; $10.1,2$ y $3 ; 12.1$ y 4 y la Disposición transitoria quinta. A lo que cabe agregar, por último, que el contenido normativo de estos preceptos no parece cuestionarse en sí mismo sino únicamente en cuanto al carácter básico que les ha atribuido la citada Disposición final tercera» (f.j. 1). 
«Ha de llegarse a la conclusión de que la declaración de inconstitucionalidad de la Disposición final tercera, por cuanto que atribuye carácter básico a una serie de actuales y futuras disposiciones reglamentarias, no significa negar a cada una de estas últimas la eficacia normativa que en cada caso y conforme a Derecho -incluidas las normas de distribución competencial aplicables- le corresponda. Siendo ajeno a un recurso de inconstitucionalidad el dilucidar, caso por caso, tal eficacia normativa» (vid. f.j. 25).

«Dado que todas las apreciaciones de motivos de inconstitucionalidad efectuadas a lo largo de la precedente fundamentación jurídica respecto de la Disposición final tercera de la Ley 34/1992, se refieren exclusivamente a las diversas atribuciones de carácter básico formuladas por el primer inciso de la misma, es a ese primer inciso al que ha de ceñirse la correspondiente declaración de inconstitucionalidad, sin perjuicio de extenderla, por conexión, a los preceptos de la misma Ley que en los precedentes fundamentos y en el fallo se indican. No afectando en consecuencia dicha declaración de inconstitucionalidad al segundo inciso de la Disposición final tercera, por el que se exceptúa de la atribución de carácter básico a determinados preceptos de la misma Ley.

Finalmente, y en cuanto a las disposiciones reglamentarias y actuaciones administrativas, en gran parte futuras, cuya imprecisa, genérica e inmotivada calificación como básicas por la Disposición final tercera también ha dado lugar a la declaración de inconstitucionalidad de esta última, la presente sentencia tampoco ha de interpretarse en el sentido de negarles absolutamente y en todo caso ese carácter. Ha de estarse, en todo caso, al examen de las mismas y, por tanto, es posible que excepcionalmente algunas de ellas pudieran llegar a obtener, en su caso, el reconocimiento de básicas» (f.j. 26).

Fallo: $10^{\circ}$ Estimar parcialmente el presente recurso de inconstitucionalidad $y$, en consecuencia:

A) Declarar que el primer inciso de la Disposición final tercera de la Ley $34 / 1992$, de 22 de diciembre, de ordenación del sector petrolero, no es conforme con el orden constitucional de competencias en tanto que atribuye carácter básico al art. 10.1, párrafo tercero (respecto al inciso final, «así como su distribución al por menor mediante suministros directos»); al art. 10. 1, párrafo cuarto («el otorgamiento de las restantes autorizaciones que no sean competencia de las Comunidades Autónomas según sus respectivos Estatutos»); al art. 10.3, párrafos primero a quinto; al inciso final del párrafo sexto del art. 10.3 («y que serán requisito para el otorgamiento por las Comunidades Autónomas de las correspondientes autorizaciones administrativas que son de su competencia»); al art. 10.3, párrafo séptimo («reglamentariamente se establecerán los procedimientos y condiciones necesarios 
RESEÑA DE SENTENCLAS DEL TRIBUNAL CONSTTTUCIONAL ...

para que dicho Registro disponga de manera inmediata de datos reales sobre los expedientes en tramitación en cada Comunidad Autónoma desde el momento de su iniciación para asegurar la aplicación del régimen uniforme de distancias establecido, el respeto estricto del criterio de prioridad en las solicitudes de inscripción establecido en la Orden Ministerial de 29 de julio de 1988 o disposiciones que la Administración dicte en su lugar y la garantía en la Resolución que se dicte de los principios de seguridad jurídica e igualdad entre las solicitudes»); y a la Disposición transitoria quinta.

B) Declarar asimismo que el inciso primero de la Disposición final tercera no es conforme con el orden constitucional de competencias en cuanto atribuye carácter básico a las disposiciones reglamentarias habilitadas en los arts. 7.1 , párrafo primero; $8.1 ; 10.3$, párrafos cuarto y séptimo; y en las Disposiciones transitorias primera y quinta; así como a las actuaciones relacionadas en el párrafo segundo del apartado 2 del art. 10, todos ellos de la mencionada Ley.

\section{Desestimar el recurso en todo lo demás.}

(Sentencia n. ${ }^{\circ}$ 197/1996, de 28 de noviembre. Pleno. BOE de 3 de enero de 1997. J. D. González Campos).

\section{D) Entidades de Crédito}

1. Conflictos positivos de competencia núms. $456 / 1988$ y 462/1988, acumulados, promovidos, respectivamente, por el Gobierno Vasco, y por el Consejo Ejecutivo de la Generalidad de Cataluña, en relación, el primero, con la Disposición adicional del Real Decreto 1369/1987, de 18 de septiembre, por el que se crea el Sistema Nacional de Compensación Electrónica y, el segundo, con los arts. 1 y 2.2 y la Disposición adicional del mismo Real Decreto. El TC declara que corresponde al Estado la titularidad de la competencia controvertida.

«Entrando ya en el análisis y enjuiciamiento de los artículos objeto del presente proceso constitucional, lo primero que debe advertirse es que la norma cuestionada tiene por finalidad -como ya nos consta - la creación en el Banco de España del Sistema Nacional de Compensación Electrónica "a través del cual se llevará a cabo la compensación de documentos, medios de pago y transmisiones de fondos que, mediante sistemas y procedimientos electrónicos, presenten al mismo las entidades miembros" (art. 1) (...) Ningún reproche de constitucionalidad cabe realizar a esta medida porque encaja en la competencia estatal relativa a las bases de la ordenación de crédito, banca y segu- 
ros (art. 149.1.11 CE) (...) La justificación de la regulación y gestión del Sistema Nacional de Compensación Electrónica en los términos contenidos en el Real Decreto 1369/1987, viene dada por las razones a las que se refiere la STC 178/1992. Basta constatar un hecho: A través de la garantía del buen funcionamiento, solvencia y eficiencia del Sistema Nacional de Compensación se pretende garantizar el buen funcionamiento, solvencia y eficiencia del sistema de pagos. No es necesario justificar la importancia que tiene este sistema respecto del conjunto del sistema económico. Por lo tanto, la regulación y gestión del Sistema Nacional de Compensación Electrónica creado por el Real Decreto 1369/1987 en los términos a los que se refiere esta norma sirve, en última instancia, a la preservación del sistema económico en su conjunto. Desde este punto de vista no cabe formular ninguna tacha de inconstitucionalidad, desde la perspectiva competencial, al art. 1 del Real Decreto impugnado» (vid. f.j. 5).

«Es cierto que, como sostiene la Generalidad de Cataluña, el art. 2.2 del Real Decreto 1369/1987, al establecer la composición de la Comisión que debe asesorar al Banco de España en la administración y gestión del Sistema Nacional de Compensación Electrónica, no ha previsto la participación en la misma de las Comunidades Autónomas y que ello se debe a que el Gobierno ha diseñado ese Sistema no en clave de coordinación de una pluralidad de sistemas territoriales, sino como un sistema "cuyo ámbito geográfico (...) se extiende a todo el territorio del Estado" (art. 1.1). El Gobierno podía, en hipótesis, haber optado por un modelo nacional en el que se articularan varios sistemas territoriales; en este supuesto, la participación autonómica en su administración y gestión hubiera sido inevitable. Sin embargo, la opción del Gobierno por tal sistema también puede sin dificultad considerarse básica, ya que, en realidad, las finalidades perseguidas al establecerlo -ofrecer un marco único y global de compensación para reducir costes, tiempo e inseguridad en las compensacionesdifícilmente cabe pensar que pudieran obtenerse con un modelo de coordinación de sistemas territoriales parciales» (f.j. 6).

«Respecto a la alegación de que, a tenor de la Disposición adicional, las Cámaras de Compensación existentes, oficiales y privadas, no podrán compensar electrónicamente los documentos, medios de pago o transmisiones de fondos para cuya compensación existan normas del Sistema Nacional, debe afirmarse que, aunque ciertamente esto es lo establecido en este precepto, ninguna tacha de inconstitucionalidad puede efectuársele ya que, como afirma el Abogado del Estado, con esta previsión se pretende garantizar que el Sistema Nacional funcione como un verdadero sistema que aspira a comprender la totalidad de las operaciones que hayan de integrarlo, evitando interferencias y duplicidades. Cabe, pues, encuadrar este segundo inciso de la Disposición adicional entre las bases de la ordenación de la banca» (f.j. 7). 
RESEÑA DE SENTENCIAS DEL TRIBUNAL CONSTITUCIONAL ...

«Finalmente, en cuanto a las autorizaciones que en el último inciso de la mencionada Disposición adicional se atribuyen al Banco de España debe concluirse: Primero, que, en relación con la relativa a la modificación del presente ámbito de actuación de las Cámaras, se trata de un acto discrecional cuya atribución al Banco de España resulta básica puesto que con esta actividad, en última instancia, se pretende garantizar el correcto funcionamiento de estos sistemas de compensación y liquidación y éstas son funciones típicas e irrenunciables del Banco de España en tanto que supervisor y garante del sistema de pagos.

Respecto a la autorización de los Convenios entre entidades, lo primero que debe tenerse presente es que el alcance de la autorización atribuida al Banco de España ha sido precisado por la norma novena, 2 del Reglamento del Sistema Nacional de Compensación Electrónica al establecer que "El Banco de España, una vez oído el correspondiente informe de la Comisión, concederá esta autorización, salvo que la iniciativa o innovación propuesta genere obligaciones, respecto de operaciones ya incluidas en el Sistema Nacional, al resto de entidades miembros de éste".

A la vista de esta configuración legal no cabe duda que la referida autorización es una actividad reglada de ejecución en materia de ordenación del crédito y la banca. Sin embargo, a pesar de este carácter ejecutivo y reglado no puede negársele el carácter básico puesto que su función no es otra que la de garantizar la integridad del Sistema Nacional evitando interferencias, derivadas de la eventual creación de obligaciones al resto de entidades miembros del mismo respecto de operaciones ya incluidas en el Sistema Nacional, que podrían poner en peligro las funciones básicas que este Sistema Nacional lleva a cabo en orden a asegurar el eficaz funcionamiento del sistema de pagos en su conjunto cuya tutela es una de las funciones fundamentales del Banco de España [arts. 7.3 b) y 16 de la Ley 13/1994, de Autonomía del Banco de España]» (f.j. 8).

Fallo: Declarar que corresponde al Estado la titularidad de la competencia controvertida en relación con los arts. 1 y 2.2 y la Disposición adicional del Real Decreto 1369/1987.

(Sentencia n. ${ }^{\circ}$ 37/1997, de 27 de febrero. Pleno. BOE de 1 de abril de 1997. C. Viver Pi- Sunyer).

\section{MEDIO AMBIENTE}

1. Recurso de inconstitucionalidad núm. 1739/1989, promovido por el Presidente del Gobierno contra los apartados 1.1.1 y 1.1.17 del articulo $1 .^{\circ}$ de la Ley del Parlamento Vasco 1/1989, de 13 de abril, porla que se modifi- 
ca la calificación de determinadas infracciones administrativas en materia de caza y pesca fluvial. El TC estima el recurso y declara inconstitucionales los incisos "calificadas como "amenazadas" por encontrarse en vías de extinción» del apartado 1.1.1 y "por encontrarse en vías de extinción» del apartado 1.1.17 de la citada Ley, por entender que dichos preceptos son contrarios a la legislación básica del Estado dictada en el ejercicio de su competencia sobre medio ambiente (art. 149.1.23 CE), asi como a las exigencias de igualdad esencial en el tratamiento administrativo-sancionador de la materia, que se derivan del art. 149.1.1 CE.

«El presente recurso de inconstitucionalidad interpuesto por el Presidente del Gobierno se dirige contra dos incisos contenidos en los apartados 1.1.1 y 1.1.17 del artículo primero de la Ley del Parlamento Vasco 1/1989. Estos preceptos regulan como infracción administrativa la caza y comercialización de especies amenazadas o en peligro de extinción, estableciendo para tales conductas una sanción (multa de 50.001 a 500.000 pesetas) notoriamente inferior a la dispuesta en la Ley del Estado 4/1989, de Conservación de los Espacios $\mathrm{Na}$ turales y de la Flora y Fauna Silvestres (multa de 10.000 .001 a 50.000 .000 de pesetas). La prohibición de cazar o pescar a los infractores tiene también un límite inferior en la Ley de la Comunidad Autónoma (hasta cinco años) al establecido en la Ley estatal (hasta diez años).

El Abogado del Estado, en la representación que ostenta, aduce dos órdenes de consideraciones para fundamentar su pretensión de inconstitucionalidad.

En primer lugar, que los preceptos impugnados contravienen la legislación básica del Estado en materia de medio ambiente (art. 149.1.23 CE) y, en particular, lo establecido en los arts. 38 y 39 de la citada Ley del Estado 4/1989. Por consiguiente, el legislador autonómico habría vulnerado el orden constitucional de distribución de competencias, invadiendo un espacio constitucionalmente reservado al Estado.

En segundo lugar, que las disposiciones legales impugnadas son contrarias al art. 149.1.1 CE, pues si bien las Comunidades Autónomas pueden adoptar normas administrativas en materia de su competencia, tales disposiciones no pueden introducir divergencias irracionales o desproporcionadas, que quiebren en lo fundamental la unidad del esquema sancionatorio» (vid. f.j. 1).

«La protección concedida por la Ley estatal puede ser ampliada y mejorada por la Ley autonómica; lo que resulta constitucionalmente improcedente es que resulte restringida o disminuida. 
RESEÑA DE SENTENCIAS DEL TRIBUNAL CONSTITUCIONAL ...

En consecuencia, y por las razones expuestas en las sentencias mencionadas, la competencia exclusiva del País Vasco sobre la caza no le permite instaurar un régimen administrativo sancionador, en materia de caza o comercialización de especies amenazadas o en peligro de extinción, que disminuya la protección de la legislación básica estatal sobre protección del medio ambiente» (vid. f.j. 2).

«La diferente cuantía de la multa establecida en la legislación autonómica vasca (de 50.001 a 500.000 pesetas) en relación con la prevista en la legislación básica del Estado (de 10.000.001 a 50.000.000 de pesetas), junto a la aminoración de las accesorias, evidencia, de modo palmario, una modificación del esquema sancionatorio que, con el carácter de básico, debe presidir la protección del medio ambiente y la represión administrativa de determinadas conductas gravemente atentatorias al mismo, como lo son la caza y comercialización de las especies amenazadas o en peligro de extinción. Los preceptos impugnados son contrarios a la legislación básica del Estado dictada en el ejercicio de su competencia sobre medio ambiente (art. 149.1.23 CE), así como a las exigencias de igualdad esencial en el tratamiento administrativo-sancionador de la materia, que se derivan del art. 149.1.1 CE. Razones ambas que conducen derechamente a la declaración de su inconstitucionalidad, por incurrir en una vulneración del referido orden constitucional de distribución de competencias» (vid. f.j. 3).

Fallo: Estimar el recurso de inconstitucionalidad y, en consecuencia, declarar inconstitucionales y nulos los incisos «calificadas como "amenazadas" por encontrarse en vías de extinción» del apartado 1.1.1 y "por encontrarse en vías de extinción», del apartado 1.1.17, ambos del art. 1. ${ }^{\circ}$ de la Ley del Parlamento Vasco 1/1989, de 13 de abril, por la que se modifica la calificación de determinadas infracciones administrativas en materia de caza y pesca fluvial, en la medida en que, por su conexión con lo establecido en el apartado 1.1 del mismo precepto, vulneran la competencia estatal de legislación básica sobre protección del medio ambiente.

(Sentencia n. ${ }^{\circ}$ 196/1996, de 28 de noviembre. Pleno. BOE de 3 de enero de 1997. M. Jiménez de Parga y Cabrera).

2. Recurso de inconstitucionalidad núm. 1834/1989, promovido por el Presidente del Gobierno contra el art. 46.2 de la Ley del Príncipado de Asturias 2/1989, de 6 de junio, de Caza. El TC declara su inconstitucionalidad en la medida en que por conexión con la sanción prevista en el párrafo primero del mismo art. 46 vulnera la competencia de legislación básica sobre protección del medio ambiente (art. 149.1.23 CE) al reducir noto- 
riamente la cuantía de la multa prevista en la legislación básica del Estado para similares conductas tipificadas como infracción administrativa.

«El precepto autonómico impugnado reduce notoriamente la cuantía de la multa prevista en la legislación básica del Estado para similares conductas tipificadas como infracción administrativa, quebrando la unidad del régimen sancionador mínimo y común en materia de medio ambiente, y que - por las razones expuestas - no puede ser desconocido por las Comunidades Autónomas en el ejercicio de aquellas otras competencias que, como la caza, inciden directamente sobre la primera. El art. 46.2. a de la Ley autonómica $2 / 1989$, disminuye sensiblemente la protección administrativo-sancionadora que dispensan los arts. 38 y 39 de la LCEN (Ley 4/1989, de 27 de marzo, de Conservación de los Espacios Naturales y de la Flora y Fauna Silvestres), incidiendo en una materia de carácter básico y reservada al Estado por el art. 149.1.23 de la Constitución, por lo que debe declararse su inconstitucionalidad al contravenir el orden constitucional de distribución de competencias» (vid. f.j. 3).

Fallo: Declarar inconstitucional y, por tanto, nulo, el art. 46.2. ${ }^{\mathrm{a}}$ de la Ley del Principado de Asturias 2/1989, de 6 de junio, de Caza, en la medida en que por conexión con la sanción prevista en el párrafo primero del mismo art. 46 vulnera la competencia estatal de legislación básica sobre protección del medio ambiente.

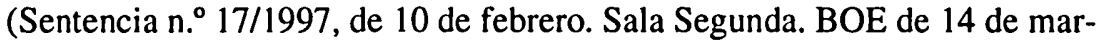
zo de 1997. R. de Mendizábal Allende).

\section{CULTURA}

1. Conflictos positivos de competencia acumulados núms. 2033/1990 y 2745/1990, promovidos ambos por el Consejo Ejecutivo de la Generalidad de Cataluña en relación, el primero, con los arts. $1 .^{\circ}$, c) y $4 .^{\circ} .2$, c) y la Sección Quinta, asi como, por conexión, los arts. $5^{\circ}$ y $99^{\circ} .4$ de la Orden del Ministerio de Cultura, de 16 de marzo de 1990, por la que se establece la normativa de ayudas al sector del libro español y, el segundo, con los arts. $6^{\circ} .2,99^{\circ} .2$ y 10 y, por conexión, el último párrafo de la disp. transit. $1 .^{a}$ de la Orden del Ministerio de Cultura, de 30 de julio de 1990, sobre ayudas financieras a la inversión en el sector del libro. El TC estima parcialmente los conflictos y declara que corresponde a la Comunidad Autónoma de Cataluña la titularidad de la competencia ejercida por el Estado en los arts. $4 .^{\circ} .2$, c), 24.1, 26.2, 28 y 29 y, por conexión con ellos, en los arts. $5^{\circ}$ y 9..$^{\circ}$ de la primera Orden Ministerial citada y en los arts. $4 .^{\circ}$, $6^{\circ} .2,9 .^{\circ} .2$ y 10 y, por conexión, en el último párrafo de la disp. transit. $1 .^{a}$ 
RESEÑA DE SENTENCIAS DEL TRIBUNAL CONSTTUCIONAL...

\section{de la segunda Orden Ministerial citada, y desestima el conflicto en todo lo demás.}

«Las ayudas se establecen, pues, para contribuir al desarrollo y modernización del sector del libro en su conjunto, pero con la finalidad explícita de difundir la cultura escrita de los distintos pueblos de España. Para alcanzar esa meta resulta menester mejorar las estructuras industriales y comerciales del sector; mas esa mejora es sólo un instrumento al servicio del fin cultural perseguido. Este carácter meramente instrumental se pone de manifiesto en el hecho de que, para conceder las ayudas, se tienen en cuenta algunos datos económicamente relevantes (volumen de facturación anual, cifra de exportación); pero, junto a ellos, se aplican otros que carecen de esa relevancia (duración e intensidad de la dedicación a las actividades del sector, fondo editorial, número de títulos en catálogo). Y hasta tal punto resulta prevalente el fin de difusión de la cultura, que es posible acceder a las ayudas sin cumplir los requisitos de otra índole establecidos en la normativa cuando se trate de proyectos de excepcional trascendencia cultural (art. 16 de la OM de 30 de julio).

Parece necesario concluir, pues, aplicando los criterios expuestos anteriormente, que el ámbito material propio de las normas reglamentarias en cuestión es el cultural y, más en concreto, el del fomento de la cultura» (vid. f.j. 2).

«En esta materia de "cultura", sin perjuicio de que la Comunidad Autónoma de Cataluña haya asumido competencia exclusiva sobre la misma (art. 9 EAC), es de tener en cuenta el mandato de la Constitución según el cual "el Estado considerará el servicio de la cultura como deber y atribución esencial y facilitará la comunicación cultural entre las Comunidades Autónomas, de acuerdo con ellas" (art. 149.2 CE). De ahí que este Tribunal haya declarado, concretamente, que corresponde al Estado la "preservación del patrimonio cultural común", así como "lo que precise de tratamientos generales o que no puedan lograrse desde otras instancias" (SSTC 49/1984, 157/1985, $107 / 1987$ y 17/1991). Junto a estas actividades, que competen en exclusiva al Estado, éste puede desempeñar también una actividad genérica de fomento y apoyo a las diversas manifestaciones culturales, aunque en este supuesto, como se dijo en la STC 109/1996 en relación a un asunto similar al aquí enjuiciado, deberá limitarse a prever las ayudas que estime pertinentes sin llevar a cabo otras actividades normativas y de gestión superpuestas o duplicadas respecto de las que corresponden a las Comunidades Autónomas con competencias en la materia de cultura.

Aplicando estas premisas al presente caso, no puede negarse en abstracto al Estado la titularidad de la competencia para adoptar las Órdenes ministeriales objeto de este proceso constitucional o, más precisamente, para otorgar las ayudas al sector del libro contenidas en las referidas Órdenes. Ciertamente, no 
se trata de una actividad de fomento que pretenda preservar el "patrimonio cultural común", ni puede afirmarse que tan sólo la actuación unitaria del Estado garantiza la consecución de sus objetivos; sin embargo, como queda dicho, ex art. 149.2 CE el Estado puede destinar estas ayudas al libro aunque, al no tratarse ya de una competencia exclusiva, el alcance de esta actividad genérica de fomento debe delimitarse con sumo cuidado. Para ello debe atenderse a la doctrina de este Tribunal en relación con la actividad estatal de subvenciones y ayudas» (f.j. 3).

«Por lo que aquí interesa, conviene retener que la regulación de las condiciones complementarias de otorgamiento, así como la tramitación y gestión de las ayudas ha de corresponder a las Comunidades Autónomas, siendo su gestión centralizada por el Estado la excepción, reservada para los casos en que resulte imprescindible para asegurar la plena efectividad de las ayudas dentro de la ordenación básica del sector y para garantizar iguales posibilidades de obtención y disfrute por parte de sus potenciales destinatarios en todo el territorio nacional, evitando al propio tiempo que se sobrepase la cuantía global de los fondos destinados al sector (STC 109/1996). En igual sentido nos hemos pronunciado en la STC 59/1995 (f.j. 5. A).

Así pues, el Estado puede regular la concesión de ayudas y subvenciones al sector del libro para fomentar la difusión de la cultura escrita común a todos los pueblos que lo conforman, pero no puede reservarse competencias de gestión salvo en los casos excepcionales que justifican su gestión centralizada, lo que habrá de parecer razonablemente justificado y deducirse sin esfuerzo de la naturaleza de la medida de fomento de que se trate (SSTC 13/1992, f.j. 8. ${ }^{\circ}$, d; 330/1993 f.j. 3. ${ }^{\circ}$; 213/1994, f.j. 4. ${ }^{\circ}$, b; 59/1995, f.j. 5. ${ }^{\circ}$, A, y 109/1996, f.j. 5. ${ }^{\circ}$ ).

De acuerdo con esta interpretación, que precisa las competencias del Estado y de las Comunidades Autónomas en esta materia, no deben tacharse de inconstitucionales, pues no invaden las competencias atribuidas estatutariamente a la Generalidad de Cataluña, los arts 1.C), 24.2, 25, 26.1 y 27 de la Orden de 16 de marzo de 1990 en cuanto se limitan a prever el establecimiento de ayudas a la gestión de los sectores de distribución y comercialización del libro, las clases de estas ayudas, su cuantía máxima, el objeto o finalidad de las mismas, los requisitos de las empresas solicitantes y los criterios esenciales para la concesión. Otro tanto cabe decir del art. 1 de la Orden de 30 de julio del mismo año, en el que, de igual forma, se contempla la posibilidad de concesión al sector del libro de las ayudas financieras a que se refiere. La posibilidad de establecer ayudas a cargo del Estado no impide, sino que facilita, el que la Generalidad de Cataluña, en ejercicio de su competencia $e x$ art. 9.4 de su Estatuto de Autonomía, establezca las condiciones complementarias de otorgamiento, la 
tramitación y resolución de las solicitudes, así como la gestión de tales subvenciones» (vid. f.j. 4).

«Ni en las Órdenes ministeriales impugnadas ni en las alegaciones que la defensa del Gobierno de la Nación ha vertido en este proceso constitucional se justifica la necesidad de que los fondos controvertidos, tal y como se establece en aquéllas, deban ser gestionados de forma centralizada y no, para el ámbito de Cataluña — que es el que aquí nos interesa-, por la Administración llamada en primer lugar a ello en virtud de sus atribuciones competenciales, es decir, la autonómica. La mayor difusión posible de los datos bibliográficos cuya gestión realiza el Ministerio de Cultura y el cumplimiento de la finalidad propia de la Agencia Española del ISBN, en definitiva, la difusión de la oferta cultural editada y su mejor conocimiento por el ciudadano, no exigen que la gestión de las ayudas articuladas al efecto deban centralizarse en la Administración del Estado sin intervención alguna de la Administración autonómica, salvo la de mero receptor de las solicitudes y la documentación aneja (art. 6.2 de la Orden de 30 de julio de 1990).

Desconocen, pues, la distribución de competencias en la materia los arts. 4.2. c), $24.1,26.2,28$ y 29 de la Orden de 16 de marzo de 1990 en cuanto crean una Comisión de Asesoramiento y Evaluación regulando su composición, le atribuyen facultades excepcionales, establecen la documentación que ha de acompañarse con la solicitud y exigen la acreditación de haber realizado la inversión en el plazo de dos meses desde que la resolución de concesión de la ayuda es notificada. Por conexión con ellos, también conculcan el orden constitucional y estatutario de distribución de competencias los arts. 5, que define las funciones de aquella Comisión, y 9.4, que exige que con la solicitud ha de acompañarse la documentación a que se refiere el art. 28.

A igual conclusión ha de llegarse respecto de los arts. 4, 6.2, 9.2 y 10 y, por conexión, el último párrafo de la Disposición transitoria primera de la Orden del Ministerio de Cultura de 30 de julio de 1990. El primero en cuanto regula las funciones de la Comisión de Asesoramiento y Evaluación; el segundo porque dispone el lugar de presentación de las solicitudes; el tercero en cuanto prevé que los servicios de las Comunidades Autónomas deben remitir al Centro del Libro y de la Lectura en un plazo de cuarenta y cinco días las solicitudes ante ellos presentadas; y el cuarto porque regula la tramitación y resolución de las solicitudes atribuyéndolas, respectivamente, a los servicios del Ministerio de Cultura y al Subsecretario del Departamento. En conexión con los anteriores preceptos también adolece de incompetencia el último párrafo de la Disposición transitoria primera de la Orden al establecer el plazo de presentación de las solicitudes, sin que haya que extender la declaración de incompetencia a otros preceptos de las Ordenes ministeriales aquí considerados, no 
incluidos por el Consejo Ejecutivo de la Generalidad de Cataluña en la relación de normas objeto de este conflicto» (f.j. 5).

Fallo: Estimar parcialmente los conflictos positivos de competencia y, en su virtud:

1. Declarar que corresponde a la Comunidad Autónoma de Cataluña la titularidad de la competencia ejercitada por el Estado en los arts. 4.2.c), 24.1, $26.2,28$ y 29 y, por conexión con ellos, en los arts. 5 y 9.4 de la Orden del Ministerio de Cultura de 16 de marzo de 1990 y en los arts. 4, 6.2, 9.2 y 10 y, por conexión, en el último párrafo de la Disposición transitoria primera de la Orden del Ministerio de Cultura de 30 de julio de 1990.

2. Desestimarlos en todo lo demás.

(Sentencia n. 71/1997, de 10 de abril. Pleno. BOE de 13 de mayo de 1997. M. Jiménez de Parga y Cabrera).

\section{UNIVERSIDADES}

1. Recurso de amparo núm. 3157/1992, interpuesto por la Universidad de Valencia contra Sentencia de 19 de mayo de 1989 de la Sala Segunda de lo Contencioso-Administrativo de la extinta Audiencia Territorial de Valencia confirmada en apelación por Sentencia de 20 de noviembre de 1992 de la Sala Tercera del Tribunal Supremo (Sección Tercera) y que declaraban nulo de pleno Derecho, por vulneración del Estatuto de Autonomía de la Comunidad Valenciana y de la Ley de las Cortes Valencianas sobre Uso y Enseñanza del Valenciano, el Acuerdo de su Junta de Gobierno de 20 de julio de 1986, en el que se admitía la denominación de "catalán» para denominar su lengua propia. El TC entiende que las Sentencias impugnadas vulneran el derecho fundamental a la autonomía universitaria, $y$, en consecuencia, otorga el amparo.

«El Acuerdo de la Junta de Gobierno de la Universidad de Valencia que fue impugnado en la vía contencioso-administrativa y el art. 7 de los Estatutos de la Universidad donde encuentra cobertura, vienen a establecer de consuno que la valenciana, lengua propia de la Comunidad Valenciana y por ello, de su Universidad, podrá ser también denominada "lengua catalana", en el ámbito universitario, sin que ello contradiga el Estatuto de Autonomía ni la Ley de las Cortes Valencianas mencionada al principio. La Universidad de Valencia no ha transformado la denominación del valenciano y se ha limitado a permitir que en su seno pueda ser conocido también como catalán, en su dimensión "acadé- 
RESEÑA DE SENTENCIAS DEL TRIBUNAL CONSTITUCIONAL ...

mica", según los propios Estatutos. No se rebasa, pues, el perímetro de la autonomía universitaria, tal y como se configura legalmente, y por tanto es indudable la validez de los preceptos en tela de juicio.

En realidad, como ya dijimos en la STC 130/1991, en un caso emparentado con el presente (determinación por la Universidad de Valencia en sus Estatutos del escudo, sello y símbolos de identidad), la cuestión discutida no es tanto el contenido material de la autonomía universitaria como el alcance del control judicial de una concreta decisión adoptada en el ejercicio de esa autonomía, control que nunca puede basarse en criterios de oportunidad y conveniencia (SSTC 26/1987, 55/1989 y 130/1991). Podrá discutirse cuanto se quiera sobre la pertinencia de que en el seno de la Universidad de Valencia la lengua propia de la Comunidad Autónoma se denomine indistintamente valenciano o catalán, pero, como ha quedado dicho, ello no contradice valores, bienes o intereses constitucionalmente tutelados y no vulnera precepto legal alguno. En consecuencia, como alega lúcidamente el Fiscal, ha de concluirse que las sentencias aquí y ahora impugnadas, donde se anula el Acuerdo correspondiente, vulneran la autonomía de la Universidad y que, en definitiva, el amparo por ella pedido debe serle otorgado» (vid. f.j. 4).

Fallo: Otorgar el amparo solicitado por la Universidad de Valencia y, en consecuencia:

1. Reconocer que las sentencias impugnadas vulneran el derecho a la autonomía de la Universidad de Valencia.

2. $\quad$ Anular la Sentencia dictada el 19 de mayo de 1989 por la Sala Segunda de lo Contencioso-Administrativo de la extinta Audiencia Territorial de Valencia, en el recurso núm. 1754/1986, y la pronunciada por la Sección Tercera de la Sala Tercera del Tribunal Supremo el 20 de noviembre de 1992, que, desestimando el recurso de apelación núm. 1473/1989 interpuesto contra aquélla, la confirmó íntegramente.

3. Que el apartado c) del Acuerdo adoptado por la Junta de Gobierno de la Universidad de Valencia el 20 de julio de 1986 no es contrario al Estatuto de Autonomía de la Comunidad Valenciana.

(Sentencia n. ${ }^{\circ} 75 / 1997$, de 21 de abril. Sala Segunda. BOE de 21 de mayo de 1997. R. de Mendizábal Allende. Voto particular formulado por J. Gabaldón López). 


\section{LENGUAS}

1. Conflicto positivo de competencia núm. 1080/1990, promovido por el Consejo Ejecutivo de la Generalidad de Cataluña, en relación con la expresión «en lengua castellana» contenida en el artículo 36.1 del Real Decreto 1597/1989, de 29 de diciembre, por el que se aprueba el Reglamento del Registro Mercantil. Sostiene el Consejo Ejecutivo, que el mandato contenido en el art. 36.1 del RRM impide que puedan extenderse los asientos registrales en catalán cuando el documento a inscribir está redactado en esa lengua, invadiéndose asi la competencia de ordenación lingüistica de la Generalidad; sostiene asimismo que el precepto en cuestión vulneraría la competencia de la Generalidad en orden a la normalización lingüística, vaciándola de contenido en el ámbito del Registro Mercantil. El TC desestima el conflicto de competencia al entender que el Estado es competente para regular lo dispuesto en el art. 36.1 del RRM y que dicho precepto no ha menoscabado la habilitación que en materia lingüistica posee la Generalidad de Cataluña.

«Se desprenden, pues, dos conclusiones. En primer lugar, como ya hemos avanzado, la competencia del Estado para determinar la lengua en la que deben practicarse los asientos en el Registro Mercantil y, más concretamente, la competencia estatal para dictar el art. 36.1 RRM objeto del presente conflicto. Así parece reconocerlo la propia Ley 7/1983, del Parlamento de Cataluña, de normalización lingüística, que, después de regular en el art. 11 la lengua oficial en la que deben redactarse los asientos en los Registros públicos dependientes de la Generalidad, se limita a prever en su disposición adicional que la misma promoverá, de acuerdo con los órganos competentes, la normalización del catalán en los registros no dependientes de la misma.

La segunda conclusión es la de que el Estado al regular el uso de la lengua en los Registros Mercantiles territoriales radicados en la Comunidad Autónoma debe respetar las cláusulas generales relativas a la oficialidad y normalización de las lenguas, que se concretan, en lo que aquí afecta y como ya hemos avanzado, en el art. 2.2 de la referida Ley $7 / 1983$ que establece que "las manifestaciones de pensamiento o de voluntad y los actos orales o escritos, públicos o privados, no pueden dar lugar en Cataluña a ningún tipo de discriminación si se expresan total o parcialmente en lengua catalana y producen todos los efectos jurídicos igual que si se expresaran en lengua castellana, $y$, por consiguiente, en lo que respecta a su eficacia, no pueden ser objeto de ningún tipo de dificultad, retraso, requerimiento de traducción ni de ninguna otra exigencia" y en el art. 8.2 y 3 , referido en general a la Administración Civil del Estado, prevé que ésta debe expedir los documentos o testimonios contenidos en los expe- 
RESEÑA DE SENTENCIAS DEL. TRIBUNAL CONSTTTUCIONAL ...

dientes por ella tramitados en el idioma oficial requerido por los ciudadanos que los soliciten.

Estas previsiones legales, que hoy continúan vigentes, y no fueron impugnadas en el recurso que en su día promovió el Presidente del Gobierno contra la citada disposición -y que este Tribunal resolvió en la STC 83/1986, sin ningún pronunciamiento en contra-, establecen pues, tan sólo tres requisitos relacionados con un conjunto de derechos linguiísticos de los ciudadanos e, indirectamente, con la oficialidad y normalización del uso del catalán, a saber: a) que los documentos redactados en catalán deben tener, a efectos registrales mercantiles, la misma eficacia y validez que los redactados en castellano; b) que los documentos expresados en catalán no pueden verse sometidos a ningún tipo de "dificultad o retraso"; y c) que las certificaciones y demás comunicaciones relativas a los asientos deben expedirse en la lengua oficial de elección del solicitante.

Debemos analizar, pues, si el art. 36.1 RRM respeta o, por el contrario, desconoce y menoscaba estas consecuencias y derechos derivados de la oficialidad del catalán» (vid. f.j. 4).

«Planteada la cuestión desde esta perspectiva cabe avanzar ya que la previsión de que los asientos deben practicarse en lengua castellana no impide que los documentos redactados en catalán tengan plenos efectos registrales, iguales en eficacia y validez que los redactados en castellano (...) Si los documentos en virtud de los que se practican los asientos agotan sus efectos en el momento en que se presentan ante el Registro y sirven de base para la calificación e inscripción, deberemos concluir que, si esos documentos pueden presentarse en catalán sin que se exija previa traducción, los documentos redactados en esta lengua tienen la misma eficacia y validez a efectos registrales que los redactados en castellano.

Pues bien, ni el RRM ni ninguna otra disposición normativa obligan a quien presenta en el Registro un documento en catalán a traducirlo previamente al castellano. Este silencio debe interpretarse en el sentido de que, efectivamente, los documentos redactados en la lengua oficial propia de la Comunidad pueden presentarse en el Registro y el Registrador deberá tomarlos como base para realizar la calificación y el asiento. Ninguna otra interpretación del silencio del RRM sería acorde con las consecuencias que derivan de la cooficialidad de las lenguas en los territorios con lengua oficial propia distinta del castellano entre las que figura, como ha reiterado este Tribunal y se acaba de recordar en fundamentos precedentes, el derecho de los ciudadanos de dirigirse a cualquier Administración en la lengua oficial que estime oportuno. Es cierto que una vez presentado en lengua distinta del castellano, el asiento se llevará a cabo en esta 
lengua pero, como queda dicho, en el momento de practicarse este asiento, el documento en cuanto tal, cualquiera que sea su lengua, ya habrá producido todos sus efectos ante el Registro» (vid. f.j. 5).

«El precepto enjuiciado plantea mayores interrogantes al enjuiciarse desde la perspectiva de la exigencia, contenida en la Ley $7 / 1983$, de normalización lingüística, de que los documentos redactados en catalán no sufran por este hecho "dificultades" o retrasos (...)

No obstante, debe reconocerse que el sistema previsto en el art. 36.1 del RRM en sí mismo considerado no produce necesariamente inseguridad jurídica ni retrasos indebidos, ni por supuesto alteración del orden de acceso al registro respecto de los documentos escritos en catalán. Por ello, desde la perspectiva propia del presente proceso constitucional basta con advertir que si el Estado opta, como ha hecho a efectos de su inscripción, por la traducción de los documentos no redactados en castellano deberá establecer los medios, personales y materiales, necesarios para que no se produzcan ni inseguridad jurídica ni retrasos.

Por último, en cuanto a los problemas relativos a la publicidad formal de los asientos debe notarse, en primer lugar, que respecto de la expedición de certificaciones de los mismos nada se opone ni en el precepto impugnado, ni en el resto del articulado del RRM, a que éstas se lleven a cabo en el idioma oficial escogido por el solicitante (...)

De cuanto se ha dicho cabe concluir que el Estado es competente para regular lo dispuesto en el art. 36.1 del RRM y que al hacerlo en la forma en que lo ha hecho no ha menoscabado la habilitación que en materia lingüística posee la Generalidad de Cataluña» (vid. f.j. 6).

Fallo: Desestimar el conflicto positivo de competencia promovido por la Generalidad de Cataluña y, en su virtud, declarar que el inciso «en lengua castellana» contenido en el art. 36.1 del Reglamento del Registro Mercantil, aprobado por el Real Decreto 1597/1989, de 29 de diciembre, no es contrario al orden constitucional y estatutario de distribución de competencias.

(Sentencia n. ${ }^{\circ} 87 / 1997$, de 24 de abril. Pleno. BOE de 21 de mayo de 1997. C. Viver Pi-Sunyer). 